\title{
Linking an economic model for European agriculture with a mechanistic model to estimate nitrogen and carbon losses from arable soils in Europe
}

\author{
A. Leip ${ }^{1}$, G. Marchi ${ }^{1}$, R. Koeble ${ }^{1, *}$, M. Kempen ${ }^{2}$, W. Britz ${ }^{2,1}$, and C. Li $^{3}$ \\ ${ }^{1}$ European Commission - DG Joint Research Centre, Institute for Environment and Sustainability, Ispra, Italy \\ ${ }^{2}$ University of Bonn, Institute for Food and Resource Economics, Bonn, Germany \\ ${ }^{3}$ Institute for the Study of Earth, Oceans, and Space, University of New Hampshire, Durham, NH 03824, USA \\ *now at: Institute of Energy Economics and the Rational Use of Energy, Department of Technology Assessment and \\ Environment, Stuttgart, Germany
}

Received: 23 May 2007 - Published in Biogeosciences Discuss.: 5 July 2007

Revised: 10 October 2007 - Accepted: 2 December 2007 - Published: 28 January 2008

\begin{abstract}
A comprehensive assessment of policy impact on greenhouse gas (GHG) emissions from agricultural soils requires careful consideration of both socio-economic aspects and the environmental heterogeneity of the landscape. We developed a modelling framework that links the large-scale economic model for agriculture CAPRI (Common Agricultural Policy Regional Impact assessment) with the biogeochemistry model DNDC (DeNitrification DeComposition) to simulate GHG fluxes, carbon stock changes and the nitrogen budget of agricultural soils in Europe. The framework allows the ex-ante simulation of agricultural or agri-environmental policy impacts on a wide range of environmental problems such as climate change (GHG emissions), air pollution and groundwater pollution. Those environmental impacts can be analyzed in the context of economic and social indicators as calculated by the economic model. The methodology consists of four steps: (i) definition of appropriate calculation units that can be considered as homogeneous in terms of economic behaviour and environmental response; (ii) downscaling of regional agricultural statistics and farm management information from a CAPRI simulation run into the spatial calculation units; (iii) designing environmental model scenarios and model runs; and finally (iv) aggregating results for interpretation. We show the first results of the nitrogen budget in croplands in fourteen countries of the European Union and discuss possibilities to improve the detailed assessment of nitrogen and carbon fluxes from European arable soils.
\end{abstract}

Correspondence to: A. Leip

(adrian.leip@jrc.it)

\section{Introduction}

Agricultural activity is responsible for environmental concern, causing among others elevated nitrate concentrations in water, emitting ammonia into the atmosphere and contributing to increase GHG concentrations in the atmosphere. The source strength of these pollutants must be assessed both under international obligations and European legislation. Recommended procedures for the estimation of GHG emissions (IPCC, 1997; 2000; 2006; EMEP/CORINAIR 2003) have a large uncertainty range. In addition, they lack the ability to differentiate regional conditions and accommodate mitigation measures. Therefore the development of reliable, independent and flexible assessment tools is needed (i) to assess the response of the environmental system to socioeconomically driven pressures, while reflecting the various feedbacks and interactions between natural drivers, (ii) to consider regional differences in the response in order to (iii) finally find regionally stratified emission factors or emission functions. Process-based models can be used for reporting GHG emissions from agricultural soils under the United Nations Framework Convention on Climate Change (Leip, 2005). Such models are adequate to analyze the impact of changing farming practices, as they are able to simulate complex interactions occurring between the environment and anthropogenic activities, but a successful application from the regional to the continental scale depends on matching agricultural activities with the environmental circumstances (Liu et al., 2006; Mulligan, 2006) and on the quality of the input data. The accuracy of simulating fluxes with process-based models such as the DNDC (Denitrification Decomposition) Model (Li et al., 1992), for example, has been shown to be especially sensitive to soil organic matter (SOM) content and

Published by Copernicus Publications on behalf of the European Geosciences Union. 
nitrogen fertilizer application rates. As the response of process based models to climate and soil parameters or agricultural management is non-linear, their application to regional averages of those input data leads to aggregation bias. Resulting uncertainties of a factor of 10 or more are common (Mulligan, 2006).

A comprehensive assessment of emissions from arable soils needs to consider the feedbacks between livestock population and cropland areas via fodder production or between stocking densities and manure application rates. Such feedbacks are inherent in large scale economic models such as CAPRI, which capture the complex interplay between the market, environmental policies and the economic behaviour of the different agents (farmers, consumers, processors) from global to regional scale.

Examples of policy-related process studies for agriculture at the continental scale exist for carbon sequestration (e.g. Smith et al., 2005b), nitrogen oxide emissions from forest soils (e.g. Kesik et al., 2005), investigating different management practices (e.g. Grant et al., 2004), or assessing global change scenarios (Schröter et al., 2005). Examples for studies regarding livestock systems can be found for dairy farming (Weiske et al., 2006) or grassland systems (Soussana et al., 2004). Integrated multi-sectoral modelling systems (eg. IMAGE, Bouwman et al., 2006; RAINS, Höglund-Isaksson et al., 2006) are limited to relatively simple parameterizations of pollutant fluxes. There are only a few examples where an overall assessment is achieved through linking economic with process-based models (e.g. Neufeldt et al., 2006; Wattenbach et al., 2007), but the area of interest is much smaller than in the present study.

This paper focuses on the methodology developed to link the large-scale regionalised economic model CAPRI to the biophysical DNDC model in order to develop a new policy impact simulation tool for the area of the European Union. The tool allows the ex-ante simulation of agricultural or agrienvironmental policy impacts on a wide range of environmental problems such as climate change (GHG emissions), air pollution and groundwater pollution. The analysis of the trade-off between the different pillars of sustainability of such policies is inherently built into the policy tool. The objectives of the present study are therefore (i) to give a detailed description the CAPRI/DNDC-EUROPE framework, including the agricultural land use map, that serves as an important element in linking both models and (ii) to critically examine the quality of the data sets that are available to drive processbased models at the continental scale in Europe.

\section{Methods}

\subsection{Models}

\subsubsection{DNDC}

The DNDC model predicts biogeochemistry in, and fluxes of carbon and nitrogen from agricultural soils. DNDC was developed in 1992 and since then has had ongoing enhancements ( $\mathrm{Li}, 2000$; Li et al., 1992, 2004, 2006). DNDC is a biogeochemistry model for agro-ecosystems that can be applied both at the plot-scale and at the regional scale. It consists of two components. The first component calculates the state of the soil-plant system such as soil chemical and physical status, vegetation growth and organic carbon mineralization, based on environmental and anthropogenic drivers (daily weather, soil properties, farm management). The second component uses the information on the soil environment to calculate the major processes involved in the exchange of GHGs with the atmosphere, i.e. nitrification, denitrification and fermentation. The model thus is able to track production, consumption and emission of carbon and nitrogen oxides, ammonia and methane. The model has been tested against numerous field data sets of nitrous oxide $\left(\mathrm{N}_{2} \mathrm{O}\right)$ emissions and soil carbon dynamics ( $\mathrm{Li}$ et al., 2005).

DNDC has been widely used for regional modelling studies in the USA (Tonitto et al., 2007), China (Li et al., 2006; Xu-Ri et al., 2003), India (Pathak et al., 2005) and Europe (Brown et al., 2002; Butterbach-Bahl et al., 2004; Neufeldt et al., 2006; Sleutel et al., 2006). The simulations reported here were done with a modified version of DNDC V.89, allowing a more flexible simulation of a large number of pixelclusters. These modifications enabled us to simulate an unlimited number of agricultural spatial modelling units with individual farm and crop parameterization and with the option to individually select up to ten different crops to be simulated within a specific calculation unit.

\subsubsection{CAPRI}

The agricultural economic model CAPRI sets a framework based on official national and international statistics, the global agricultural market and trade systems, and the agricultural policy environment and responses of agents (farmers, consumers, processors) to changes in policies and markets. The main purpose of CAPRI is the Pan-European exante policy impact assessment from regional to global scale. Policies considered include premiums paid to farmers, border protection by tariffs, and agri-environmental legislation. CAPRI is operationally installed at the European Commission and has been used in a wide range of studies and research projects, e.g. in a recent study by DG-Environment on ammonia abatement measures. In this study we use averaged data of the years 2001-2003. A detailed description of the CAPRI modelling system is given in Britz (2005). 


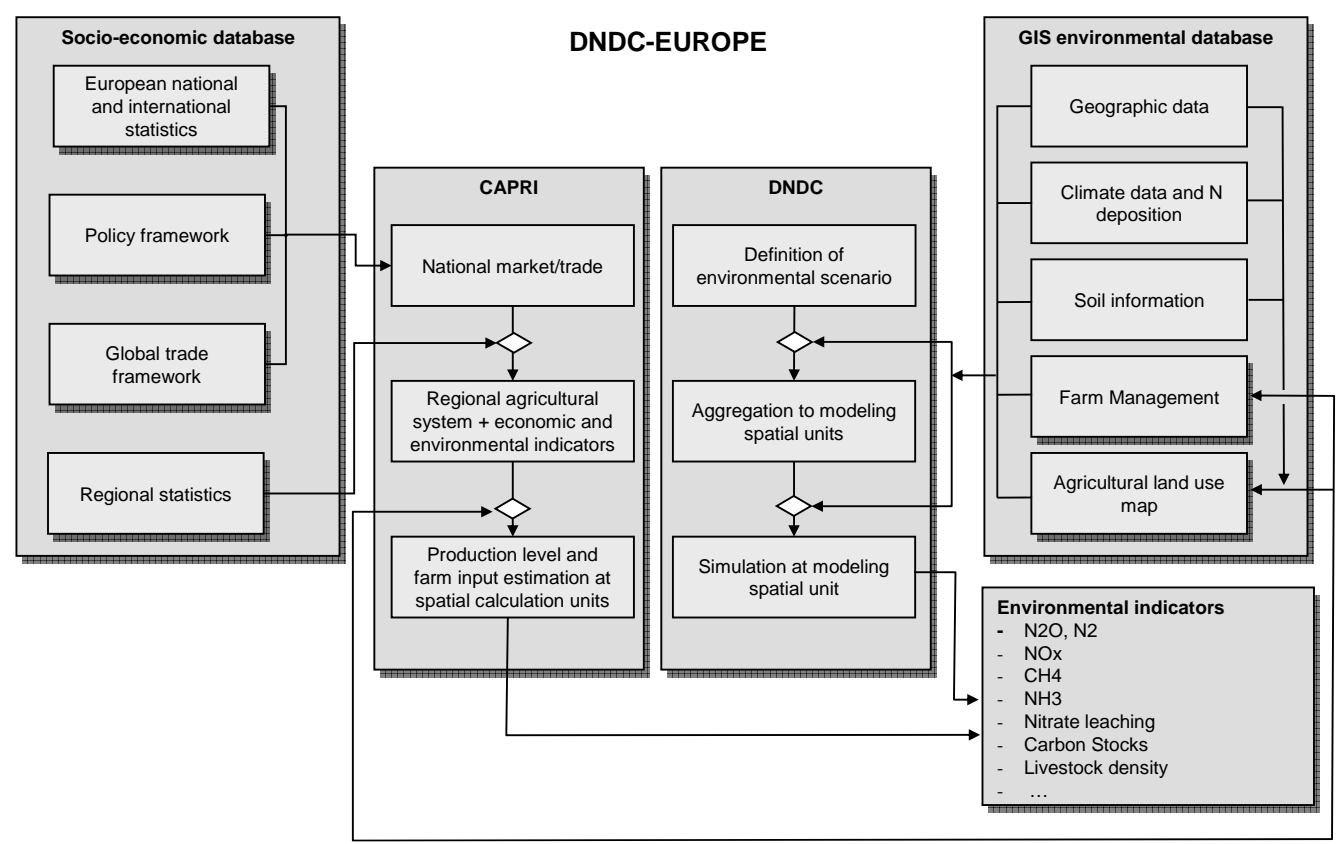

Fig. 1. Flow-diagram of the CAPRI-DNDC-EUROPE framework.

The modelling framework aims also at depicting the flow of nutrients through the production systems. Improvements on some elements have been achieved in the present study, as described below, and a spatial layer was added.

\subsubsection{CAPRI DNDC-EUROPE model link}

We combine a socio-economic database, defined at the level of administrative regions and designed to drive the economic model CAPRI, and an environmental database in a Geographical Information System (GIS) environment, which is mainly used to drive the process-based model DNDC. The environmental database also contains agricultural land use and livestock density maps, which are derived using econometric methodologies as described in Sect. 2.3. Environmental and land use/management information are used together with the estimates of production levels and farm input (see Sect. 2.4.1) at the scale of the spatial calculation units, which are obtained within the CAPRI modelling framework, to define the scenario and set-up the aggregation level and final input database to run the DNDC model (Sect. 2.6). An overview of the link between the two models is given in Fig. 1. The set of environmental indicators contains both data on soil fluxes calculated with the process-based model and emissions from livestock production systems.

\subsection{The spatial calculation unit}

The smallest unit at which agricultural statistics for EU Member States are available are the so-called Nomenclature of Territorial Units for Statistics (NUTS) regions level two or three, which correspond to administrative areas of $160 \mathrm{~km}^{2}$ to
$440 \mathrm{~km}^{2}$ (NUTS2) or $32 \mathrm{~km}^{2}$ to $165 \mathrm{~km}^{2}$ (NUTS3). Areas of this size span a wide range of natural conditions: soil type, climate and also landscape morphology. We chose four delimiters to define a spatial calculation unit, denoted as "Homogeneous Spatial Mapping Unit" (HSMU), i.e. soil, slope, land cover and administrative boundaries. The HSMU is regarded as similar both in terms of agronomic practices and the natural environment, embracing conditions that lead to similar emissions of GHGs or other pollutants.

The HSMUs were built from four major data sources, which were available for the area of the European Union, i.e. the European Soil Database V2.0 (European Commission, 2004) with about 900 Soil Mapping Units (SMU), the CORINE Land Cover map (European Topic Centre on Terrestrial Environment, 2000), administrative boundaries (EC, 2003; Statistical Office of the European Communities (EUROSTAT), 2003), and a $250 \mathrm{~m}$ Digital Elevation Model (CCM DEM 250, 2004). Prior to further processing, all maps were re-sampled to a $1 \mathrm{~km}$ raster map (ETRS89 Lambert Azimuthal Equal Area 52N 10E, Annoni, 2005) geographically consistent with the European Reference Grid and Coordinate Reference System proposed under INSPIRE (Infrastructure for Spatial Information in the European Community, Commission of the European Communities, 2004).

One HSMU is defined as the intersection of a soil mapping unit, one of 44 CORINE land cover classes, administrative boundaries at the NUTS 2 or 3 level and the slope according to the classification $0^{\circ}, 1^{\circ}, 2-3^{\circ}, 4-8^{\circ}$ and $>8^{\circ}$. As the HSMU of at least two single pixel of one square $\mathrm{km}$ are not necessarily contiguous, we can speak of the HSMU as a "pixel cluster". 


\subsection{Estimating agricultural production}

\subsubsection{Crop levels}

Statistical information about agricultural production was obtained at the regional NUTS 2 level from the CAPRI database. This database contains official data obtained from the European statistical offices (available at http:// epp.eurostat.ec.europa.eu) and has been checked for completeness and inherent consistency and complemented with management data to make them useful for modelling purposes (Britz et al., 2002).

Data on crop areas are downscaled to the level of the HSMU using a two-step statistical approach combining prior estimates based on observed behaviour with a reconciliation procedure achieving consistency between the scales (Kempen et al., 2007).

The first step develops statistical regression models to estimate the probability that a crop is grown in an HSMU as a function of environmental characteristics (climate, soil properties, land cover, etc.). The model parameters are calibrated with observational data from the Land Use/Cover Area Frame Statistical Survey (LUCAS, European Commission, 2003). To account for the possibility that factors other than natural conditions influence the choice of farmers to grow a specific crop, the weight of LUCAS observations is discounted with the distance from the respective HSMUs (Locally Weighted Binomial Logit Models, e.g. Anselin et al., 2004). Based on these parameters the first and second moments of a priori estimates of the land use shares are calculated for each HSMU and for each of the 29 crops for which statistical information is available.

In the second step consistency with the regional statistics is then obtained with a Bayesian Highest Posterior Density (HDP) estimator. The final results are (with respect to the a priori information) the most probable combination of cropping shares at HSMU level which exhaust the agricultural area of each HSMU and are in line with given regional crop and land use data or projections.

The area under analysis covers 25 Member States of the European Union; Malta and Cyprus are not included. As explained above, land cover is one of the delineation factors for the HSMUs which allowed exclusions of such HSMUs where we assumed that no agricultural cover should be present. However, a rather wide range of land cover classes comprising 11 agricultural or mixed agricultural CORINE land cover classes and 7 non-agricultural classes was maintained. As the definition of a CORINE mapping unit requires a minimum of 25 ha of homogeneous land cover, spatial units might include fractions of other CORINE classes, e.g. it is typical to find some grassland in forest areas and vice versa. In regions with predominantly forest land cover, significant percentages of grassland reported in agricultural statistics might be "hidden" in CORINE forest classes while in regions with prevailing "pasture" according to CORINE this share might be negligible. The overall procedure tries to eliminate these negligible fractions of land use from the HSMU by manipulating the prior expectations.

\subsubsection{Estimating animal stocking densities}

Manure availability is linked to livestock density and we assume a close link between local manure availability and local application rates. Unlike crops, there is no common PanEuropean data base available with high spatial resolution data on animal herds, necessary for the estimation of local parameter sets of regression functions for animal stocking densities. Instead, data on herd sizes from the Farm Structure Survey (FSS) at NUTS 2 or 3 level (about 1000 regions for EU25) were regressed against data which are available or can be estimated at the level of single HSMUs: crop shares, crop yields, climate, slope, elevation and economic indicators for group of crops as revenues or gross margins per hectare. All explanatory variables are offered in linear and quadratic form as well as square roots to an estimator which uses backward elimination. Generally the estimation is done per single Member State; however, in cases where not enough FSS regions are available for a Member State, countries are grouped during the estimation. The regression is applied to the 14 animal activities covered in the CAPRI data base as well as for livestock aggregates (ruminants, nonruminants and all types of animals) on the basis of livestock units (LUs). The vast majority of the regressions yield adjusted $R^{2}$ above $80 \%$. As expected, a low share of explained variance was found in a number of cases for area independent livestock systems (pigs, poultry).

Because the variance of explanatory variables at the HSMU level is far greater than in the FSS region sample per Member States, estimating at a single HSMU level would be prone to yield outliers with a high variance of forecast error. The forecast for stocking densities of different animals per HSMU were therefore obtained by using a distance- and size-weighted average of the explanatory variables of the surrounding HSMUs. As for crops, the forecasts per HSMU must recover the herds at the NUTS 2 level to yield consistent downscaling. In order to do so, a Highest Posterior Density estimator was used, which corrects the forecasts to match the regional herds, taking into account the variance of the forecast error when determining the correction factor per HSMU and animal type.

\subsubsection{Potential yield}

DNDC simulates the crop growth at a daily time step, using a pre-defined logistic function (S-curve) representing a trajectory to maximum obtainable nitrogen uptake and biomass carbon. Partitioning total biomass into the plant's compartments (root, shoot, grain) at harvesting time is also given as default data in the crop library files (Li et al., 2004). In the absence of any limiting factors (nitrogen, soil water, 
radiation, etc.) the pre-defined total plant carbon will be realized at harvest time. If any stress of temperature, water or nitrogen occurs during the simulated crop-growing season, a reduction of the biomass will be quantified by DNDC. Information of potential yields for soil polygons was obtained from the JRC crop growth monitoring system (Genovese et al., 2007). This was used to down-scale statistical production data at the regional level in CAPRI to the scale of HSMUs.

\subsection{Estimating agricultural management}

The DNDC model requires the following agricultural management parameters: application rates and timing of mineral and organic fertilizer, tillage timing and technique, irrigation, sowing and harvesting dates. Additional data, such as information on crop phenology, are optional.

\subsubsection{Calculation of mineral and organic fertilizer applica- tion rates}

Estimation of nitrogen application rate per crop at HSMU level is based on a spatial dis-aggregation of estimated application rates at the regional (NUTS 2) level from the CAPRI regional data base. As there are no Pan-European statistics on regional application rates available, the estimation process in CAPRI at the NUTS 2 level is briefly described. The challenge is to define application rates that are consistent with given boundary data - national mineral fertiliser use and manure nitrogen excreted from animals - cover crop needs, and lead to a plausible distribution of nitrogen losses over crops and regions. The estimation is based on the Highest Posterior Density Estimator. Manure nitrogen in a region is defined as the difference between nitrogen intake via feed - either concentrates or regionally produced fodder - and nitrogen removals by selling animal products according to a farmgate balance approach. Assuming no trade of nutrients across NUTS 2 boundaries, the available organic nitrogen must be exhausted by the estimated organic application rates. The same holds at the national level for total mineral nitrogen use in agriculture. Estimates at the Member State level on mineral application rate for selected crops or groups of crops are available from the International Fertilizer Manufacturers Organization (FAO/IFA/IFDC/IPI/PPI, 2002) which also provides statistics on total mineral fertilizer use in agriculture. The HDP estimator is set up as to minimize simultaneously the differences between the estimated and given national application rates and to stay close to typical shares of crop needs covered by organic nitrogen and assumed regional surpluses, ensuring via constraints that crop needs are covered and the available mineral and organic nitrogen is distributed. Upper bounds on organic application rates reflecting the $\mathrm{Ni}$ trate Directive are introduced for NUTS 2 regions comprising nitrate vulnerable zones.

At the HSMU level, nitrogen removals per crop are defined from the estimated crop yields. In order to determine manure

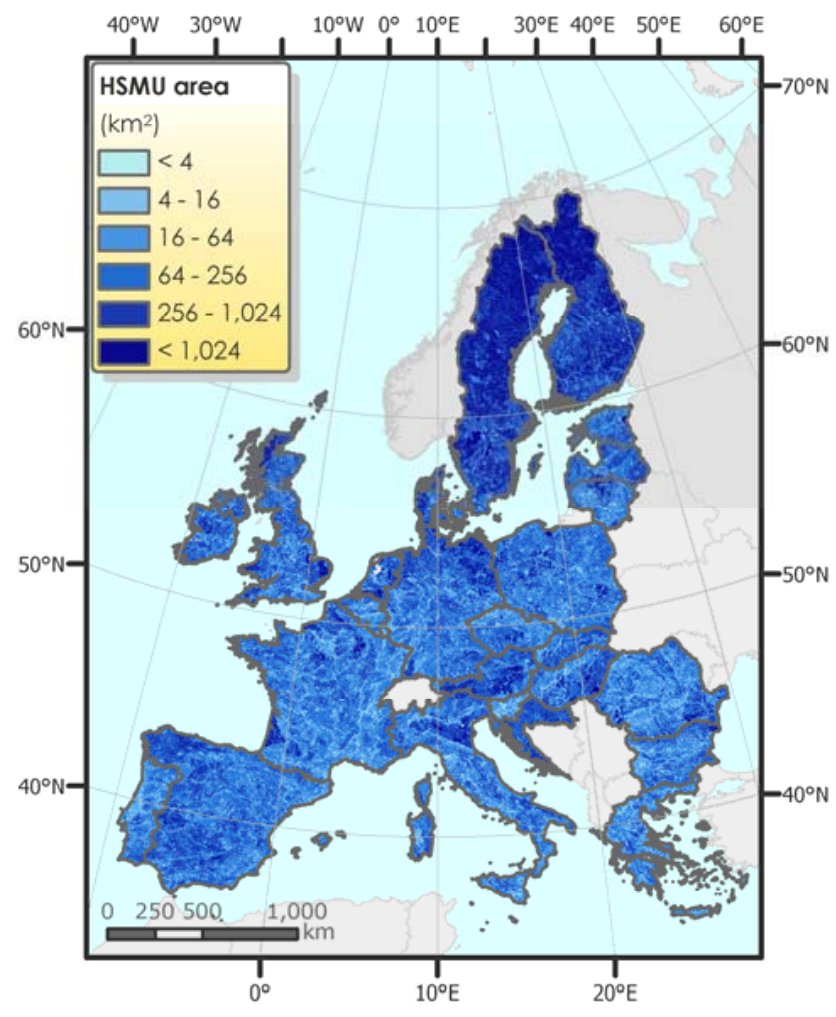

Fig. 2. Size distribution of homogeneous spatial mapping units with CCM 250 DEM hillshade.

organic application rates per crop and HSMU, we first estimate average manure application rate per crop for the NUTS 2 regions surrounding the HSMU, using the inverse distance in kilometre multiplied with the size of NUTS 2 region in square kilometre as weights. The same weights are used to define the average organic nitrogen available per hectare in the regions surrounding the HSMU. The manure application rate per crop in each HSMU is obtained by the multiplication of three terms, i.e. (i) the average organic application rate in the surrounding regions as defined above; (ii) the relation between the crop specific nitrogen removal at HSMU yield and the removal at NUTS 2 yield; and (iii) a term depending on the relation between the organic nitrogen availability per hectare at HSMU level, which is obtained from animal stocking density in the HSMU, the average manure availability as described above, and the size of the HSMU. The resulting estimated crop specific organic application rates per crop and HSMU are scaled with a uniform factor to match the given regional application rates. Summarizing, organic rates at the HSMU level will exceed average NUTS 2 rates if yields are higher - leading to higher nitrogen crop removal - or if stocking densities are higher - driving up organic nitrogen availability.

Mineral application rates are calculated as the difference between crop removals plus the relative surplus estimated at regional level minus the estimated application rate of manure 
nitrogen. Ammonia losses and atmospheric deposition are taken into account. Those estimates are increased in cases that assumed minimum application rates are not reached. As with organic rates, a uniform scaling factor lines up the HSMU-specific estimates with the regional ones.

\subsubsection{Field management}

Crop sowing and harvesting dates are obtained from Bouraoui and Aloe (2007). Scheduling of crop management is calculated by applying pre-defined time lags between crop sowing and tillage or fertilizer applications. These are obtained from the DNDC farm library (Li et al., 2004). Irrigation is treated in the DNDC model such that a calculated water deficit is replenished whenever it occurs. Irrigated crops do not suffer any water deficit while non-irrigated cultivations will endure water-stress when water demand by the plants exceeds water supply. The percentage of irrigated area was calculated on the basis of the map of irrigated areas (Siebert et al., 2005) and was taken as fixed for all crops being cultivated within a HSMU.

\subsubsection{Other management data}

All other information needed to describe farm management and crop growth, such as tillage technique, maximum rooting depth and so on, are taken from the DNDC default library and used as a constant for each crop for the entire simulated area.

\subsection{Environmental input data}

\subsubsection{Nitrogen deposition}

Data on nitrogen concentration in precipitation were obtained from the Co-operative Programme for the Monitoring and Evaluation of the Long-Range Transmission of Air Pollutants in Europe (EMEP, 2001). EMEP reports the data as precipitation weighted arithmetic mean values in $\mathrm{mg} \mathrm{NL}^{-1}$ as ammonium and nitrate measured at one of the permanent EMEP stations. We used the European coverage processed by Mulligan (2006).

\subsubsection{Weather data}

Daily weather data for the year 2000 were obtained from the Joint Research Centre (Institute for Protection and Security of the Citizen). The data originate from more than 1500 weather stations across Europe, which were spatially interpolated onto a $50 \mathrm{~km} \times 50 \mathrm{~km}$ grid by selecting the best combination of meteorological stations for each grid (Orlandi and Van der Goot, 2003).

\subsubsection{Soil data}

The DNDC model requires initial content of total soil organic carbon (SOC) data in $\mathrm{kg} \mathrm{C} \mathrm{kg}^{-1}$ of soil, including litter residue, microbes, humads and passive humus in the topsoil layer, clay content (\%), bulk density $\left(\mathrm{g} \mathrm{cm}^{-3}\right)$ and $\mathrm{pH}$. Such data were obtained from a series of $1 \mathrm{~km} \times 1 \mathrm{~km}$ soil raster data sets that were processed on the basis of the European Soil Database ${ }^{1}$ (Hiederer et al., 2003). Data on packing density and base saturation had been used by Mulligan (2006) to obtain dry bulk density and $\mathrm{pH}$, respectively, using linear relationships. Soil organic carbon content was derived using an extended CORINE land cover dataset, a Digital Elevation Model and mean annual temperature data (Jones et al., 2005). As DNDC has been parameterized for mineral soils, we restricted the simulations to spatial units with a topsoil organic content of less than $200 \mathrm{t} \mathrm{ha}^{-1}$ (Smith et al., 2005a). These data were used to initialize soil characteristics and soil carbon pools by means of a 98 year spin-up run.

\subsection{Model set-up}

The above-defined HSMU can be regarded as the smallest unit on which simulations can be carried out. However, the practicality of this is compromised by the large number of units and scenarios, and more so when a multi-year simulation is carried out. Therefore, an intermediate step re-aggregates similar HSMUs into Model Simulation Units (MSUs) on the basis of both agronomic and environmental criteria. In this way the design of the scenario calculations can better fit the objectives of the study. Within one MSU, the variability of environmental characteristics is kept at a minimum on the basis of pre-defined tolerances (Table 1). The HSMUs were regarded as similar if topsoil organic matter content differed by less than $\pm 10 \%$ and clay content, $\mathrm{pH}$ and bulk density by less than $\pm 20 \%$. The table shows also the threshold values for the minimum percentage of agricultural area and the minimum crop share, as well as additional thresholds ensuring that all significant agricultural activities are included in the simulations. These moderate tolerances and thresholds led to an average of more than 68 (up to 266) different soil conditions that were distinguished in each region, which translates to 11438 environmental situations for EU15, out of which $6391 \mathrm{MSU}$ were simulated with a total of 11063 crop-MSU combinations.

We had complete information for 14 European countries that were members of the European Union in 2004: Austria, Belgium, Finland, France, Germany, Greece, Luxembourg (simulated as part of Belgium), Italy, Netherlands, Portugal, Spain, Sweden, and United Kingdom. Statistical and weather information were centred on the year 2000. HSMU data for Ireland and the countries that joined the European Union in 2004 or 2007 have also been processed but are not yet included in the current simulation run. We simulated the following crops: cereals (soft and durum wheat, barley, oats, rye, maize and rice), oil seeds (rape and sunflower), legumi-

\footnotetext{
${ }^{1}$ Distribution version 2.0, http://eusoils.jrc.it/ESDB_Archive/ ESDB/index.htm
} 
Table 1. Thresholds and tolerances used to cluster HSMUs into MSUs and to select the simulated crops.

\begin{tabular}{llr}
\hline Parameter & Explanation & Value \\
\hline MINUAAR & Minimum UAAR in a MSU for simulation & 0.40 \\
MINSHAR & Minimum share of crop in UAAR of the MSU & 0.35 \\
MINPLUS & Minimum share of crop in UAAR not yet considered & 0.85 \\
MINMINS & Limitation share to add more crops if not relevant in region & 0.05 \\
M-ID & Tolerance for daily weather condition (file-number) & 0.05 \\
NDEP & Tolerance for N-deposition values [mg N / ml rain-water] & 0.05 \\
OC_MAX & Tolerance for soil organic carbon content & 0.10 \\
CL_MAX & Tolerance for clay content & 0.20 \\
PH_MAX & Tolerance for topsoil pH & 0.20 \\
BD_MAX & Tolerance for topsoil bulk density & 0.20 \\
\hline
\end{tabular}
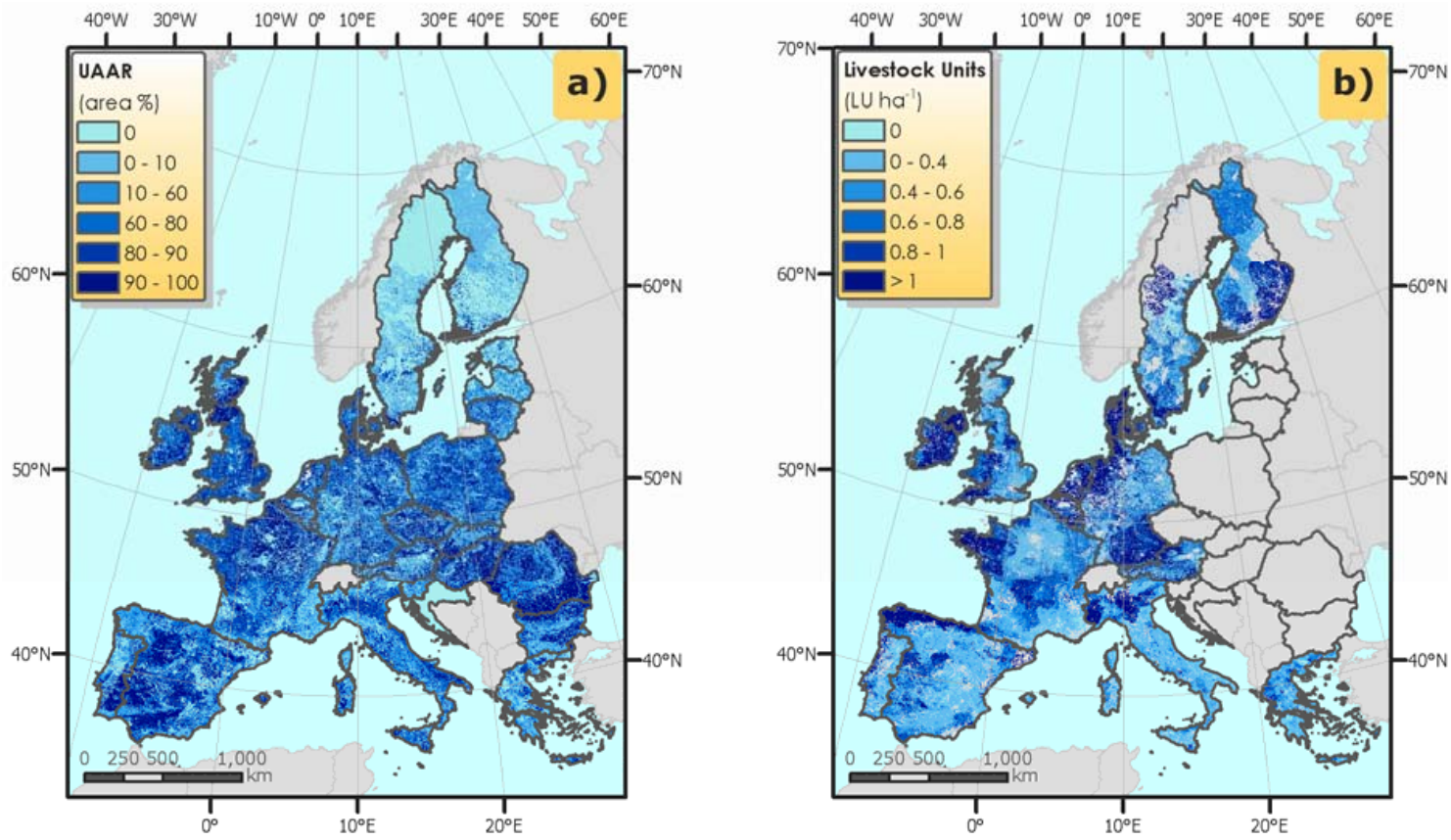

Fig. 3. (a) UAAR (b) Livestock density in EU27, superimposed on a hill-shade.

nous crops (soybean, pulses), sugar beets, potatoes, vegetables and fodder production on arable land.

Each scenario was calculated under irrigated and nonirrigated conditions and the two simulations weighted according to the irrigation map. Simulation results were aggregated to the scale of the regions or countries as areaweighted averages.

\section{Results}

\subsection{Homogeneous spatial mapping units}

The HSMUs span a wide range of sizes from a minimum area of $1 \mathrm{~km}^{2}$ to some very large areas (up to $9723 \mathrm{~km}^{2}$ ) in regions with a homogeneous landscape in terms of land cover and soil. The mean area of a HSMU indicates the range of environmental diversity with regard to land cover, administrative, data, soil and slope, and ranges from $7 \mathrm{~km}^{2}$ for Slovenia to $94 \mathrm{~km}^{2}$ for Finland with an European average around $21 \mathrm{~km}^{2}$ (see Table 2 and Fig. 2). In total, 206000 HSMUs covering almost 4.3 million $\mathrm{km}^{2}$ in Europe were defined. Small discrepancies in the surface area of countries stem from rounding errors during the re-sampling procedure and are higher in areas with a high geographical fragmentation (e.g. small islands, complex coastlines or borders). For EU27 we obtained in total about 138000 HSMUs in which agricultural activities (arable land and grassland) occur, occupying about $77 \%$ of the European landscape. 
Table 2. Main statistics on the layer of the homogeneous spatial mapping units (HMSUs) for EU27 without Malta and Cyprus.

\begin{tabular}{|c|c|c|c|c|c|c|c|c|}
\hline Country & $\begin{array}{r}\text { Number } \\
{[\mathrm{n}]}\end{array}$ & $\begin{array}{r}\text { Total Area } \\
{\left[1000 \mathrm{~km}^{2}\right]}\end{array}$ & $\begin{array}{r}\text { Mean Size } \\
{\left[\mathrm{km}^{2}\right]}\end{array}$ & $\begin{array}{r}\text { Number } \\
{[\mathrm{n}]}\end{array}$ & $\begin{array}{r}\text { Mean Size } \\
{\left[\mathrm{km}^{2}\right]}\end{array}$ & $\begin{array}{r}\text { Total Area } \\
{\left[1000 \mathrm{~km}^{2}\right]}\end{array}$ & $\begin{array}{r}\text { Mean UAAR } \\
{[\%]}\end{array}$ & $\begin{array}{r}\text { Total UAAR } \\
{\left[1000 \mathrm{~km}^{2}\right]}\end{array}$ \\
\hline & \multicolumn{3}{|c|}{ ALL HSMUs } & \multicolumn{5}{|c|}{ HSMUs with potential agricultural activities } \\
\hline Austria & 2820 & 83.6 & 29.6 & 1917 & 38.1 & 73.0 & 45 & 32.5 \\
\hline Belgium & 2245 & 30.6 & 13.6 & 1503 & 16.1 & 24.1 & 54 & 13.0 \\
\hline Bulgaria & 7275 & 110.6 & 15.2 & 5637 & 18.4 & 103.7 & 52 & 53.8 \\
\hline Czech Rep. & 5268 & 78.9 & 15.0 & 3974 & 18.5 & 73.4 & 53 & 38.8 \\
\hline Denmark & 1884 & 40.6 & 21.5 & 1152 & 32.0 & 36.8 & 69 & 25.5 \\
\hline Estonia & 1825 & 42.1 & 23.1 & 1341 & 29.2 & 39.2 & 19 & 7.6 \\
\hline Finland & 3545 & 334.1 & 94.2 & 2114 & 129.8 & 274.5 & 8 & 21.9 \\
\hline France & 35012 & 546.7 & 15.6 & 26431 & 19.2 & 506.2 & 55 & 276.4 \\
\hline Germany & 17441 & 356.2 & 20.4 & 12171 & 26.4 & 321.4 & 53 & 170.4 \\
\hline Greece & 10337 & 125.0 & 12.1 & 8456 & 14.1 & 118.9 & 30 & 35.3 \\
\hline Hungary & 5310 & 92.4 & 17.4 & 3807 & 22.3 & 85.0 & 68 & 57.9 \\
\hline Ireland & 3458 & 68.5 & 19.8 & 2336 & 23.2 & 54.1 & 71 & 38.4 \\
\hline Italy & 19890 & 297.8 & 15.0 & 14873 & 18.2 & 270.0 & 48 & 129.5 \\
\hline Latvia & 1940 & 64.0 & 33.0 & 1423 & 42.5 & 60.5 & 26 & 15.9 \\
\hline Lithuania & 3788 & 64.6 & 17.1 & 2816 & 2.16 & 60.7 & 46 & 27.7 \\
\hline Luxembourg & 323 & 2.6 & 8.0 & 243 & 9.7 & 2.4 & 54 & 1.3 \\
\hline Netherlands & 1546 & 34.3 & 22.2 & 834 & 34.2 & 28.5 & 70 & 20.0 \\
\hline Poland & 15457 & 311.6 & 20.2 & 11753 & 25.1 & 295.3 & 58 & 170.6 \\
\hline Portugal & 6570 & 88.2 & 13.4 & 5433 & 15.4 & 83.5 & 44 & 37.0 \\
\hline Romania & 16421 & 237.9 & 14.5 & 12130 & 17.7 & 215.0 & 68 & 146.9 \\
\hline Slovakia & 2604 & 49.0 & 18.8 & 1913 & 23.9 & 45.8 & 49 & 22.4 \\
\hline Slovenia & 2866 & 20.2 & 7.1 & 2495 & 7.8 & 19.4 & 27 & 5.1 \\
\hline Spain & 21205 & 496.7 & 23.4 & 16959 & 27.5 & 473.7 & 55 & 259.5 \\
\hline Sweden & 5299 & 445.0 & 84.0 & 3179 & 114.2 & 362.9 & 8 & 30.4 \\
\hline United Kingdom & 11960 & 239.9 & 20.1 & 7933 & 26.5 & 210.6 & 74 & 155.7 \\
\hline TOTAL & 206289 & 4261.0 & 20.7 & 152823 & 25.1 & 3838.4 & $47 \%$ & 1793.5 \\
\hline
\end{tabular}

\subsection{Land use and livestock density maps}

Figure 3 shows a summary of the land use and livestock density maps as total utilizable agricultural area (UAAR) and total Livestock Units (LU ha ${ }^{-1}$ ) in Europe. The average UAAR amounts to $47 \%$, with national values ranging from $8 \%$ in Finland and Sweden to more than $70 \%$ in United Kingdom and Ireland. There are differences between the "old" Member States (EU15), members of the European Union before 1 May 2004 and the "new" Member States that became member of the EU at or after this date (EU12). For EU15, $75 \%$ of the area belongs to a spatial unit with some agricultural use, a quarter of which has a UAAR less than or equal to $5 \%$. Higher average shares of UAAR are found for EU12 countries, where most of the surface is covered by HSMUs with some agricultural use $(89 \%)$ with only one-tenth having $5 \%$ or less of agricultural land use. Specific examples of agricultural land use maps obtained are shown in Fig. 4 for barley and permanent grassland for the year 2000.

The livestock density maps highlight the huge variability in stocking densities found in Europe as a result of differences in farming systems and natural conditions. The highest stocking densities are found in parts of Netherlands, Belgium, some German counties close to Netherlands and Bel- gium, Bretagne and the Po Plain in Italy. In such cases, mixed farming systems are found both featuring ruminants and non-ruminants, and with fattening processes based on concentrates. The lowest stocking densities are linked to regions where specialized crop farms are the main production system, often found where, over time, large-scale arable farming under favourable conditions has developed.

\subsection{Results input data}

\subsubsection{Nitrogen application}

On average $106 \mathrm{~kg} \mathrm{~N}$ of mineral fertilizer and $61 \mathrm{~kg} \mathrm{~N}$ contained in manure are applied per hectare to agricultural land in Europe. Hence the share of manure nitrogen in the total nitrogen application is $37 \%$, which is similar to the $33 \%$ share reported in the national GHG inventory of the European Communities (EEA, 2006). Obviously, there are large differences between different countries, according to the intensity of livestock production, as well as among crops. Table 3 shows the average national nitrogen application rates for mineral fertilizer and manure by crop. Belgium, Denmark and Netherlands are able to cover most of their nitrogen 

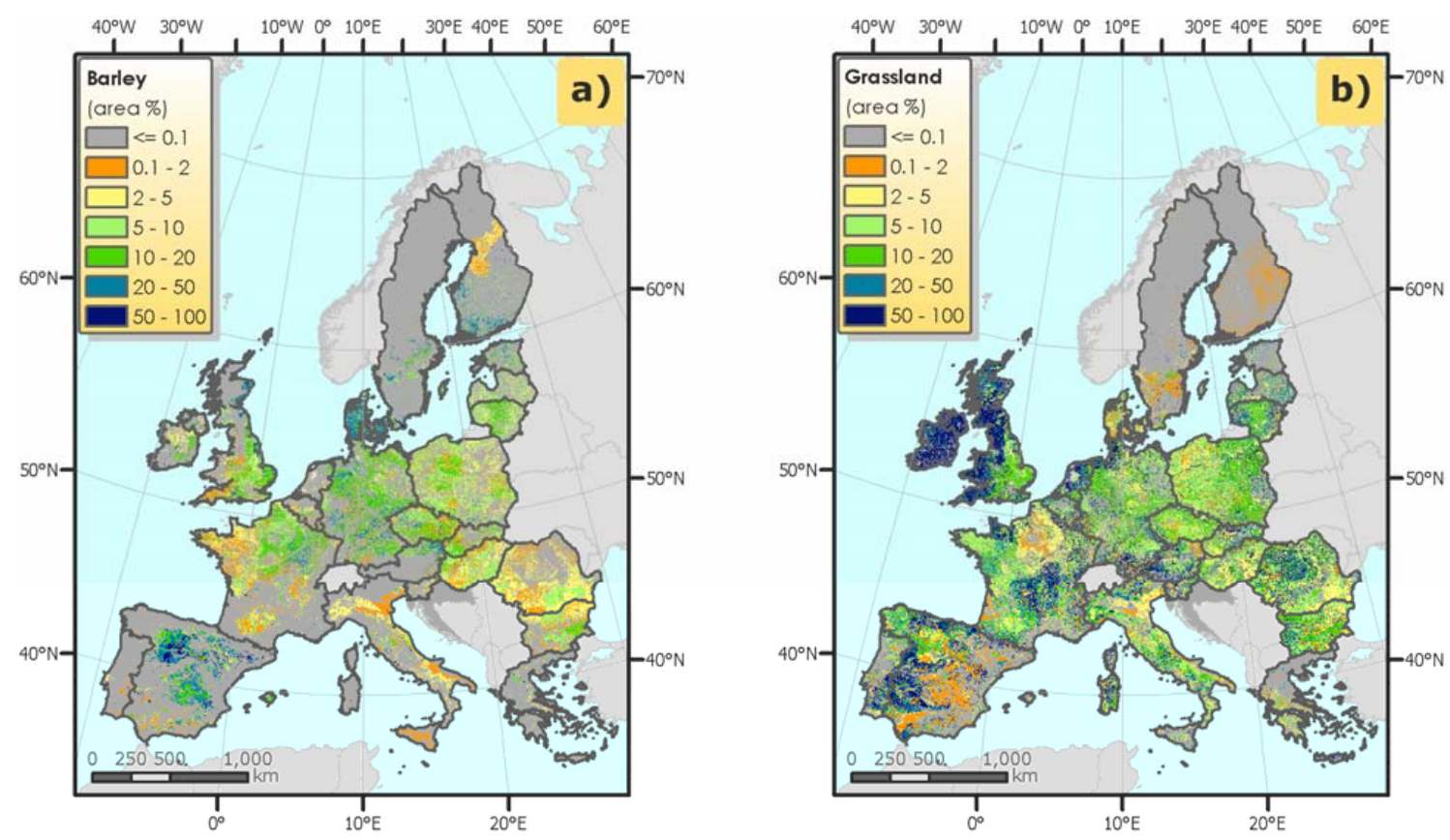

Fig. 4. Examples for the land use map: (a) barley, (b) permanent grassland.

needs by using manure; France, Portugal and United Kingdom must purchase most of the applied nitrogen from mineral sources.

The low average manure application rates in countries like France, Portugal and United Kingdom can be explained by several factors. First, compared to Belgium, Denmark and Netherlands, the average livestock densities are considerable lower. Second, stocking densities are dominated by ruminants which are linked to grassland. And third, the main arable cropping regions are dominated by specialized farms without animals, especially in France and United Kingdom.

\subsubsection{Export of nitrogen with harvested material}

Plants nitrogen uptake is the largest single pathway of nitrogen added or recycled during a year. With an average of $233 \mathrm{~kg} \mathrm{Nha}^{-1} \mathrm{y}^{-1}$ for all countries and crops simulated, it balances approximately the total input of nitrogen by mineral fertilizer and manure application, nitrogen fixation and nitrogen deposition $\left(217 \mathrm{~kg} \mathrm{Nha}^{-1} \mathrm{y}^{-1}\right.$; see Table 4$)$. The ratio of nitrogen uptake to nitrogen delivery is highest for cereals such as rye and barley where twice as much nitrogen is contained in the plant than was added to the system. Sunflower and paddy rice, on the other hand, took up only half of the applied nitrogen. Obviously a large part of the nitrogen that accumulates in the biomass will remain in the system as only a - crop-dependent - fraction is removed at harvest. Furthermore, recycling of nitrogen in the soil (mineralization of organic matter and crop residues) contributes differently to the pool of available nitrogen.

For all crops considered, the amount of nitrogen in the harvested material was from $40 \%$ to $70 \%$ of the total plant nitro- gen. For the above-ground biomass which is not harvested, it was assumed that $90 \%$ of the crop residues was left on the field (Li et al., 1994). These figures suggest a simulated nitrogen surplus between $15 \%$ for oats and more than $80 \%$ for sunflower. Nitrogen surplus pathways will be discussed in more detail in Sect. 3.4.

As described above, nitrogen application rates were calculated as a function of the estimated (above-ground) nitrogen uptake. This information was translated into potential total plant carbon to be achieved without environmental stress. Generally the reduction in assimilated plant carbon from the optimal situation was relatively stable for the different crops. Looking at all simulations, plant biomass was only $66 \%$ of the potential value. Most cereals (soft wheat, durum wheat, rye and barley) had approximately $70 \%-80 \%$ of the optimal yield, with maize and durum wheat scoring lowest. These crops achieved only half of the potential biomass, similar to potatoes and sugar beet. Paddy rice and soya were closest to their potential biomass carbon (approximately 90\%). In most cases the model was able to achieve the pre-defined distribution of carbon over the plant components (root, shoot and grain), which shows that the phenology provided to the model (sowing and harvest dates) corresponds to the parameterization of plant development. Problems were observed only for crops growing in Finland, where plant maturation was simulated too slowly, resulting in larger fractions of carbon allocated in root and shoot.

\subsubsection{Topsoil organic carbon content}

We simulated a loss of SOC of $25 \%$ or $23 \mathrm{tCha}^{-1}$ during the 98 -year spin-up simulations using constant weather 
Table 3. Application of mineral fertilizer and manure nitrogen $\left[\mathrm{kg} \mathrm{N} \mathrm{ha}^{-1}\right]$.

\begin{tabular}{|c|c|c|c|c|c|c|c|c|c|c|c|c|c|c|c|c|c|c|}
\hline & $\mathrm{N}$-input* & SWHE & DWHE & RYEM & BARL & OATS & MAIZ & PARI & RAPE & SUNF & SOYA & PULS & POTA & SUGB & TOMA & OVEG & OFAR & Average \\
\hline \multirow[t]{2}{*}{ Austria } & (a) & 73 & 75 & 36 & 69 & 48 & 83 & & 68 & 83 & 144 & 59 & 65 & 137 & 210 & 76 & 19 & 75 \\
\hline & (b) & 6 & 24 & 12 & 25 & 17 & 101 & & 33 & 20 & 27 & 48 & 12 & 30 & 16 & 5 & 53 & 38 \\
\hline \multirow[t]{2}{*}{ Belgium $^{\$}$} & (a) & 230 & & 82 & 24 & 99 & 12 & & 154 & & & 7 & 39 & 164 & 500 & 15 & 288 & 58 \\
\hline & (b) & 11 & & 31 & 64 & 43 & 411 & & 80 & & & 118 & 346 & 171 & 73 & 105 & 49 & 318 \\
\hline \multirow[t]{2}{*}{ Denmark } & (a) & 113 & & 38 & 53 & 9 & 46 & & 121 & & & & 186 & & 340 & & 36 & 79 \\
\hline & (b) & 161 & & 61 & 123 & 112 & 57 & & 344 & & & & 299 & & 304 & & 225 & 177 \\
\hline \multirow[t]{2}{*}{ Finland } & (a) & 125 & & 46 & 83 & 82 & & & 65 & 35 & & 26 & 53 & 62 & 432 & 59 & 29 & 81 \\
\hline & (b) & 45 & & 3 & 24 & 43 & & & 20 & 47 & & 48 & 56 & 16 & 9 & 1 & 61 & 33 \\
\hline \multirow[t]{2}{*}{ France } & (a) & 192 & 115 & 80 & 140 & 79 & 138 & & 96 & 101 & 190 & 2 & 100 & 130 & 163 & 40 & 79 & 156 \\
\hline & (b) & 9 & 15 & 10 & 10 & 19 & 61 & & 37 & 39 & 48 & 18 & 95 & 86 & 139 & 14 & 37 & 28 \\
\hline \multirow[t]{2}{*}{ Germany } & (a) & 274 & 176 & 169 & 92 & 114 & 44 & & 152 & 129 & & 44 & 95 & 161 & 279 & 47 & 154 & 183 \\
\hline & (b) & 14 & 13 & 20 & 6 & 10 & 175 & & 65 & 97 & & 32 & 107 & 113 & 65 & 30 & 79 & 54 \\
\hline \multirow[t]{2}{*}{ Greece } & (a) & 63 & 47 & 147 & 47 & 18 & 146 & 145 & & 23 & 236 & & 90 & 110 & 129 & 56 & 44 & 56 \\
\hline & (b) & 9 & 17 & 34 & 1 & 5 & 1 & 1 & & 9 & 14 & 1 & 10 & 1 & 1 & & 8 & 15 \\
\hline \multirow[t]{2}{*}{ Ireland } & (a) & 210 & & & 210 & 191 & & & & & & & 75 & 54 & 223 & 44 & 121 & 131 \\
\hline & (b) & & & & & & & & & & & & 23 & 15 & 2 & 2 & 78 & 67 \\
\hline \multirow[t]{2}{*}{ Italy } & (a) & 134 & 67 & 87 & 145 & 95 & 132 & 184 & 54 & 136 & 269 & 21 & 171 & 104 & 188 & 45 & 34 & 94 \\
\hline & (b) & 1 & 3 & 4 & 2 & 7 & 163 & 157 & 27 & 61 & 49 & 4 & 119 & 79 & 49 & 60 & 48 & 66 \\
\hline \multirow[t]{2}{*}{ Netherlands } & (a) & 186 & & 41 & 66 & 163 & 50 & & 79 & & & 78 & 207 & 466 & 343 & 75 & 343 & 119 \\
\hline & (b) & 173 & & & & 56 & 301 & & 163 & & & 116 & 178 & 15 & 272 & 123 & 216 & 214 \\
\hline \multirow[t]{2}{*}{ Portugal } & (a) & 34 & 29 & 32 & 34 & 16 & 112 & 118 & & & & & 9 & 66 & 6 & & 64 & 97 \\
\hline & (b) & 1 & 0 & & 26 & & 20 & 35 & & & & & & & & & 27 & 18 \\
\hline \multirow[t]{2}{*}{ Spain } & (a) & 65 & 40 & 100 & 59 & 59 & 227 & 147 & 59 & 31 & 111 & 5 & 44 & 125 & 186 & 69 & 73 & 60 \\
\hline & (b) & 7 & 0 & 26 & 10 & 7 & 54 & 136 & 46 & 34 & 31 & 59 & 62 & 27 & 20 & 169 & 26 & 14 \\
\hline \multirow[t]{2}{*}{ Sweden } & (a) & 182 & & 67 & 98 & 70 & & 56 & & & & & & 81 & 399 & 90 & 47 & 63 \\
\hline & (b) & 76 & & 5 & 39 & 41 & & 52 & & & & & & 5 & 4 & 1 & 80 & 65 \\
\hline United & (a) & 123 & 197 & 72 & 91 & 71 & 59 & & 115 & 65 & 72 & & 107 & 24 & 307 & 31 & 60 & 104 \\
\hline & (b) & 23 & 11 & 7 & 11 & 25 & 40 & & 20 & 95 & 47 & & 65 & 13 & 22 & 23 & 26 & 20 \\
\hline \multirow{2}{*}{ Average } & (a) & 171 & 61 & 152 & 64 & 92 & 113 & 177 & 131 & 51 & 173 & 18 & 126 & 119 & 205 & 54 & 55 & 106 \\
\hline & (b) & 48 & 5 & 19 & 22 & 27 & 138 & 157 & 52 & 36 & 37 & 26 & 143 & 65 & 53 & 61 & 108 & 61 \\
\hline
\end{tabular}

*(a) Mineral fertilizer nitrogen; (b) Manure nitrogen; \$: Luxembourg included in the numbers of Belgium; SHWE: soft wheat, DWHE: durum wheat, OCER: other cereals, BARL: barley, RYEM: rye, OATS: oats, MAIZ: maize; PARI: paddy rice, SUNF: sun flower, SOYA: soya, POTA: potatoes, SUGB: sugar beet, ROOF: root fodder crops, TOMA: tomatoes, OVEG, other vegetables, OFAR: fodder on arable land.

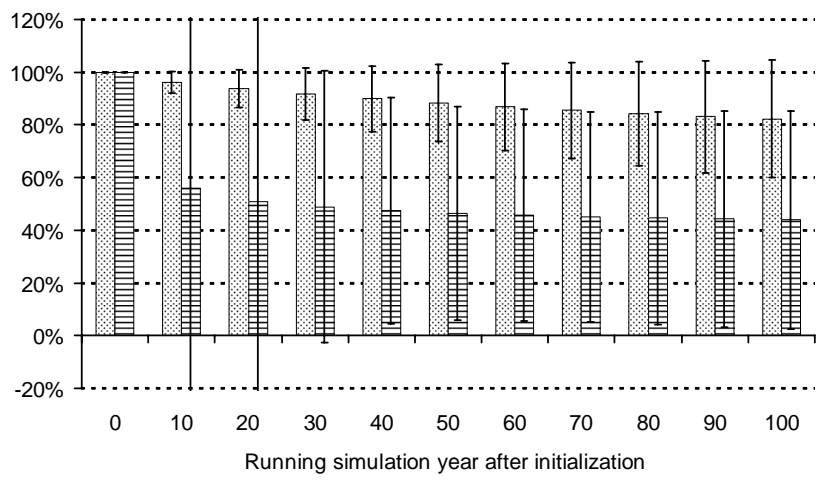

Relative decrease of soil organic carbon stocks $\boxminus$ Relative decrease of $\mathrm{N} 2 \mathrm{O}$ fluxes

Fig. 5. Soil organic carbon content in the top $30 \mathrm{~cm}$ of soils (dotted symbols) and $\mathrm{N}_{2} \mathrm{O}$ flux from the soil surface (dashed symbols), both relative to the situation in the initial simulation year.

and management data. Losses of organic carbon through mineralization processes were very high in the first simulation years with an average loss of $0.5 \mathrm{tC} \mathrm{ha}^{-1} \mathrm{y}^{-1}$ during the first decade slowing down to $0.1 \mathrm{tC} \mathrm{ha}^{-1} \mathrm{y}^{-1}$ during the last decade. The latter value is close to estimates of current carbon losses from European croplands (Vleeshouwers and Verhagen, 2002; see also Smith et al., 2005a). Fig-

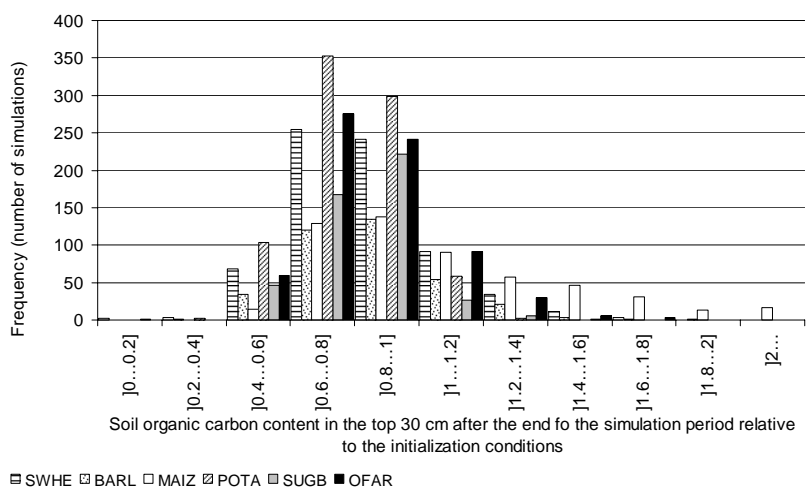

Fig. 6. Histogram for relative changes in soil organic carbon in the top $30 \mathrm{~cm}$ of soil for selected crops. SWHE: soft wheat; BARL: barley; MAIZ: maize; POTA: potatoes; SUGB: sugar beet; OFAR: fodder on arable land.

ure 5 (dotted symbols) shows that after a 98 years simulation, the average soil organic carbon stocks in the top $30 \mathrm{~cm}$ over all spatial simulation units dropped from $93 \pm 45 \mathrm{tC} \mathrm{ha}^{-1}$ to $70 \pm 30 \mathrm{tC} \mathrm{ha}^{-1}$. Only $15 \%$ of the simulations showed an increase of SOC. The distribution of relative changes for selected crops is slightly skewed (Fig. 6). Significant increases 
in SOC ( $>50 \%$ of the initial value) occurred only for maize. The majority of simulation units stayed within $20 \%$ of the initial carbon content.

The dashed symbols in Fig. 5 show the impact of declining SOM content on simulated $\mathrm{N}_{2} \mathrm{O}$ fluxes relative to the initial situation over all simulated spatial modelling units. The average $\mathrm{N}_{2} \mathrm{O}$ flux declines faster than the average relative $\mathrm{N}_{2} \mathrm{O}$ flux in the single spatial modelling units. While initial $\mathrm{N}_{2} \mathrm{O}$ fluxes were $17 \mathrm{~kg} \mathrm{~N}-\mathrm{N}_{2} \mathrm{Oha}^{-1} \mathrm{y}^{-1}$, they were reduced after the 98 year simulation to $2.8 \mathrm{~kg} \mathrm{~N}-\mathrm{N}_{2} \mathrm{O} \mathrm{ha}^{-1} \mathrm{y}^{-1}$. This suggests that some un-realistically high topsoil organic carbon estimates led to extremely high $\mathrm{N}_{2} \mathrm{O}$ fluxes in the first years of the spin-up simulation but declined quickly thereafter, diminishing their weight in the mean $\mathrm{N}_{2} \mathrm{O}$ flux. Spatial variability is very high throughout the years, though it decreases with time. The standard deviation of the average decrease of the relative $\mathrm{N}_{2} \mathrm{O}$ flux is $200 \%$ in the tenth year, reflecting large reductions in a few modelling units and smaller reductions in many more modelling units. $\mathrm{N}_{2} \mathrm{O}$ fluxes and the standard deviation of mean $\mathrm{N}_{2} \mathrm{O}$ fluxes are relatively stable after 50 simulation years.

\subsection{Simulation results}

All of the results presented in this section are related to the first simulation year after the 98 years spin-up run. Since this is a methodological paper, we restrict the presentation of the simulated nitrogen budget to the national scale. Table 4 shows a summary of the quantified, i.e. reported elements in the $\mathrm{N}$ budget aggregated to the country scale. Outputs of nitrogen by nitrogen losses and export by plant material either through plant products or crop residues are compared to nitrogen inputs via nitrogen application, deposition, fixation and release of nitrogen through net mineralization of SOM. Net mineralization of organic matter leads in some countries to a loss of nitrogen if SOM has been simulated to build up in that country. The two sides of the balance are large fluxes of nitrogen and span a large range from $77 \mathrm{~kg} \mathrm{Nha}^{-1} \mathrm{y}^{-1}$ (Greece) to $430 \mathrm{~kg} \mathrm{Nha}^{-1} \mathrm{y}^{-1}$ (Belgium). The export of nitrogen with the crop has been calculated as the residual from the difference between nitrogen inputs and outputs to close the nitrogen budget at the soil surface. Errors may occur, due to unaccounted sources or sinks of nitrogen in the simulations, such as allocation of biologically fixed nitrogen in soil compartments or leaching of organic matter. However, these discrepancies are considered to be minimal, as was found in simulations where crop development was suppressed. Here the nitrogen was essentially balanced. Additionally, $\mathrm{C} / \mathrm{N}$ ratios of the exported plant biomass were in most cases identical to or slightly higher than the pre-defined $\mathrm{C} / \mathrm{N}$ ratios in grain (due to the higher $\mathrm{C} / \mathrm{N}$ ratio in plant shoot biomass). Therefore, the error introduced by using a constant $\mathrm{C} / \mathrm{N}$ ratio for mineralized soil organic matter is likely to be small. DNDC simulates different pools of organic mat- ter with defined $\mathrm{C} / \mathrm{N}$ ratios. The $\mathrm{C} / \mathrm{N}$ ratio of litter varies from very labile $(\mathrm{C} / \mathrm{N}=5)$ through labile $(\mathrm{C} / \mathrm{N}=50)$ to resistant litter $(\mathrm{C} / \mathrm{N}=200)$. Other compartments comprise microbial biomass, humads and humus, which are all characterized by a $\mathrm{C} / \mathrm{N}$ ratio of 12 .

Nitrogen surplus is generally an important indicator of the environmental impact of agriculture on one hand, and of the effectiveness of environmental policies on the other hand. Calculating the nitrogen surplus as the ratio of nitrogen not taken up by plants (both in harvested material and in removed crop residues) to the total nitrogen input during the simulation year, gave results ranging between 26\% (United Kingdom) and 55\% (Italy). The regional average nitrogen surplus was $38 \%$.

\section{Discussion}

\subsection{Spatial simulation units}

Regional or (sub)continental modelling studies often run their model on a regular grid of varying size depending on the area covered by the format of available data sets and the scope of the simulations. Roelandt et al. (2006) for example worked on predicting future $\mathrm{N}_{2} \mathrm{O}$ emissions from Belgium relying on climate scenarios that were available for a 10' longitude and latitude grid, while Kesik et al. (2005) linked the simulation of nitrogen oxides emissions from European forest soils to the available climate data set and ran the model on a $50 \mathrm{~km} \times 50 \mathrm{~km}$ raster. Vuichard et al. (2007) estimated the GHG balance of European grasslands but due to computing limitations they restricted the simulations to a $1^{\circ} \times 1^{\circ}$ grid. These approaches are efficient for fast responses to possible developments or for delivering a first estimate of largescale emissions. For detailed analysis, however, they lack the link to realistic land use data (Roelandt et al., 2006) and are too coarse for capturing local heterogeneities (Vuichard et al., 2007). For a better representation of land use, many authors run their models within the administrative boundaries for which regional statistics are available. Examples of this approach include simulation studies on about 2500 Chinese counties to estimate soil organic carbon storage (Tang et al., 2006) or GHG emissions from rice cultivation ( $\mathrm{Li}$ et al., 2006) using the DNDC model. To assess regional heterogeneity, the Most Sensitive Factor method (Li et al., 2005) is used giving a reasonable range of emission values with a high probability to capture the true value. This "administrative approach" is also used if the study aims to give support to, or for comparison with, national GHG estimates performed with the IPCC emission-factor approach (e.g. Li et al., 2001; Brown et al., 2002; Del Grosso et al., 2005; Mulligan, 2006). Mulligan points out, however, that most of the uncertainty in the emission estimates stem from the large range of environmental conditions encountered within a single modelling unit. 
Table 4. Summary of the quantified nitrogen budget, aggregated to country-scale. All values are given in $\mathrm{kg} \mathrm{N}^{-} \mathrm{ha}^{-}$.

\begin{tabular}{|c|c|c|c|c|c|c|c|c|c|c|c|}
\hline All crops & $\begin{array}{l}\text { Mineral } \\
\text { fertilizer }\end{array}$ & Manure & N-fixation & Deposition & $\begin{array}{r}\text { Mineraliza } \\
\text { tion \$ }\end{array}$ & Leaching & $\mathrm{NH}_{3}$ & $\mathrm{~N}_{2}$ & $\mathrm{NO}$ & $\mathrm{N}_{2} \mathrm{O}$ & $\begin{array}{r}\text { Export by } \\
\text { harves }\end{array}$ \\
\hline & \multicolumn{4}{|c|}{ Nitrogen input } & \multicolumn{7}{|c|}{ Nitrogen output } \\
\hline Austria & 75.5 & 37.8 & 19.6 & 9.9 & 4.5 & 16.1 & 29.4 & 6.6 & 0.5 & 4.1 & 90.5 \\
\hline Belgium & 57.6 & 318.1 & 29.4 & 26.6 & -2.2 & 76.4 & 93.3 & 8.8 & 1.6 & 10.5 & 238.8 \\
\hline Denmark & 79.0 & 177.4 & 107.9 & 6.8 & 8.0 & 101.4 & 47.2 & 4.8 & 0.6 & 2.9 & 222.2 \\
\hline Finland & 80.6 & 32.8 & 2.6 & 1.4 & 38.3 & 27.1 & 10.5 & 65.6 & 0.6 & 5.1 & 46.9 \\
\hline France & 155.8 & 28.2 & 41.0 & 10.9 & -0.9 & 19.2 & 47.4 & 2.8 & 0.4 & 2.7 & 162.5 \\
\hline Germany & 182.6 & 54.1 & 13.7 & 11.2 & 11.6 & 16.9 & 50.9 & 6.3 & 0.6 & 4.6 & 194.1 \\
\hline Greece & 55.8 & 14.6 & 3.5 & 2.6 & 0.6 & 16.9 & 17.0 & 2.3 & 0.5 & 4.2 & 36.3 \\
\hline Italy & 94.0 & 66.0 & 19.1 & 13.8 & -9.1 & 19.1 & 67.2 & 5.9 & 0.6 & 3.8 & 87.2 \\
\hline Netherlands & 118.7 & 214.4 & 12.1 & 26.7 & 17.1 & 61.1 & 39.7 & 15.5 & 1.8 & 15.8 & 255.2 \\
\hline Portugal & 97.2 & 18.2 & 27.0 & 15.1 & -0.4 & 26.2 & 29.6 & 2.5 & 0.4 & 2.2 & 96.2 \\
\hline Spain & 60.3 & 13.6 & 6.2 & 4.6 & 0.5 & 5.0 & 30.5 & 1.8 & 0.2 & 1.4 & 46.2 \\
\hline Sweden & 62.5 & 64.5 & 151.9 & 3.7 & 40.0 & 102.3 & 8.6 & 27.9 & 0.6 & 3.0 & 180.2 \\
\hline UK & 103.7 & 20.1 & 17.8 & 8.9 & 10.5 & 17.3 & 30.8 & 0.9 & 0.2 & 0.9 & 110.8 \\
\hline Average & 106.1 & 61.4 & 40.8 & 9.1 & 6.1 & 36.0 & 42.3 & 6.6 & 0.5 & 3.1 & 135.0 \\
\hline
\end{tabular}

\$ Net mineralization calculated from simulated changes in soil organic stocks using an average soil C/N ratio of 12 .

To overcome these problems, other studies have used the geometry of the available information on soil properties to delineate the modelling units used. For large-scale application, as in the Grant et al. (2004) assessment of the impact of agricultural management on $\mathrm{N}_{2} \mathrm{O}$ and $\mathrm{CO}_{2}$ emissions in Canada, representative soil type and soil texture combinations were defined covering the seven major soil regions in Canada. Changes in soil organic carbon stocks or fluxes of GHGs were estimated on the basis of landscape units generated by an intersection of a land-use map and a soil map for Belgium (Lettens et al., 2005) or a region in Germany (Bareth et al., 2001). An additional intersection with a climate map was done in a study on $\mathrm{N}_{2} \mathrm{O}$ emissions from agriculture in Scotland (Lilly et al., 2003). So far, however, these very detailed analyses were restricted to relatively small countries or regions due to limitations of computing resources.

Schmid et al. (2006) describe a very detailed approach to simulate soil processes in Europe with the biophysical model EPIC. By intersecting landscape variables that are considered stable over time (elevation, slope, soil texture, depth of soil and volume of stones in the subsoil) they obtained a layer of more than 1000 homogeneous response units. Each of these units was divided, on average, into 10 individual simulation units by overlaying various maps such as climate, land cover, land use/management and administrative boundaries. Individual simulation units were then regarded as representative field sites and the estimated field impact from simulated management practices was uniformly extrapolated to the entire unit.

Our approach has many similarities to the approach described by Schmid et al. (2006); in both cases the philosophy is to develop a framework integrating both environmental and socio-economic impacts on soil processes. The main differences, however, are the following:

- In Schmid et al. (2006), selected soil characteristics are used to delineate the homogeneous response units, while in the present study each geometrical unit of the soil database (the so-called SMU) is maintained in the delineation of the homogeneous spatial mapping units defined. Each SMU is a unique combination of one or several soil types. Preliminary land use simulations suggested that soil type is an integrative characteristic with relevance for both the agronomic-based choice of the use of the land and for the environmental response to agronomic pressures, yielding more reliable land use estimates. Unfortunately, soil types within an SMU are not geo-referenced and soil characteristics in use (texture, topsoil organic carbon content, etc.) are defined at the scale of the SMU only. Integration of the pedotransfer functions into the land use mapping model and consistent estimation of soil characteristics at the level of soil types will be one of the major improvements to the present approach in the near future.

- The time window for which our methodology is applicable is rather narrow and linked - through the CAPRI model - to the time horizon of agricultural projections, usually about 10 years. However, the methodology used for downscaling the regional information to the spatial calculation units could easily be incorporated in any other socio-economic modelling framework, provided that the main driving parameters are consistently calculated (mineral fertilizer consumption and manure 
Table 5. Main statistics on the layer of the homogeneous spatial mapping units (HMSUs) for EU27 without Malta and Cyprus.

\begin{tabular}{|c|c|c|c|c|}
\hline CORINE CLASS & $\mathrm{km}^{2}$ & $\%$ UAAR & LAND USE CLASS & cumulative $\%$ \\
\hline \multirow[t]{2}{*}{$\begin{array}{l}\text { NON-IRRIGATED } \\
\text { ARABLE LAND }\end{array}$} & \multirow[t]{2}{*}{565782} & \multirow[t]{2}{*}{44.9} & $\begin{array}{l}\text { Soft Wheat } \\
\text { Barley } \\
\text { Fallow Land } \\
\text { Grassland } \\
\text { Maize }\end{array}$ & 60.8 \\
\hline & & & $\begin{array}{l}\text { Other Fodder On Arable Land } \\
\text { Rape } \\
\text { Durum Wheat } \\
\text { Oats } \\
\text { Sugar Beet }\end{array}$ & 85.6 \\
\hline \multirow[t]{2}{*}{ PASTURES } & \multirow[t]{2}{*}{209930} & \multirow[t]{2}{*}{16.7} & $\begin{array}{l}\text { Grassland } \\
\text { Other Fodder On Arable Land } \\
\text { Maize } \\
\text { Soft Wheat } \\
\text { Barley }\end{array}$ & 98.6 \\
\hline & & & $\begin{array}{l}\text { Other Cereals } \\
\text { Oats } \\
\text { Fallow Land } \\
\text { Durum Wheat } \\
\text { Fruit Trees }\end{array}$ & 99.7 \\
\hline \multirow[t]{2}{*}{$\begin{array}{l}\text { COMPLEX CULTIVATION } \\
\text { PATTERNS }\end{array}$} & \multirow[t]{2}{*}{134759} & \multirow[t]{2}{*}{10.7} & $\begin{array}{l}\text { Grassland } \\
\text { Other Fodder On Arable Land } \\
\text { Maize } \\
\text { Soft Wheat } \\
\text { Barley }\end{array}$ & 67.9 \\
\hline & & & $\begin{array}{l}\text { Vineyards } \\
\text { Olive Groves } \\
\text { Fallow Land } \\
\text { Fruit Trees } \\
\text { Durum Wheat }\end{array}$ & 91.4 \\
\hline \multirow[t]{2}{*}{\begin{tabular}{llr} 
LAND & \multicolumn{2}{c}{ PRINCIPALLY } \\
OCCUPIED & BY & AGRI- \\
CULTURE, WITH & SIG- \\
NIFICANT & AREAS OF \\
NATURAL VEGETATION
\end{tabular}} & \multirow[t]{2}{*}{56783} & \multirow[t]{2}{*}{4.5} & $\begin{array}{l}\text { Grassland } \\
\text { Other Fodder On Arable Land } \\
\text { Fallow Land } \\
\text { Barley } \\
\text { Olive Groves }\end{array}$ & 78.9 \\
\hline & & & $\begin{array}{l}\text { Soft Wheat } \\
\text { Oats } \\
\text { Maize } \\
\text { Fruit Trees } \\
\text { Durum Wheat }\end{array}$ & 94.5 \\
\hline \multirow[t]{2}{*}{ NATURAL GRASSLAND } & \multirow[t]{2}{*}{52320} & \multirow[t]{2}{*}{4.1} & $\begin{array}{l}\text { Grassland } \\
\text { Other Fodder On Arable Land } \\
\text { Fallow Land } \\
\text { Durum Wheat } \\
\text { Soft Wheat }\end{array}$ & 98.5 \\
\hline & & & $\begin{array}{l}\text { Maize } \\
\text { Olive Groves } \\
\text { Rye } \\
\text { Barley } \\
\text { Other Cereals }\end{array}$ & 99.8 \\
\hline
\end{tabular}


Table 6. Application rates of mineral fertilizer nitrogen for selected crops/countries $\left[\mathrm{kg} \mathrm{N} \mathrm{ha}^{-1}\right]$ (Source: FAO/IFA/IFDC/IPI/PPI, 2002).

\begin{tabular}{lrrrrrrrrrr}
\hline & Wheat & Barley & Maize & Rape & Pulses & Potatoes & Sugar b. & Veget. & Fodder & Total \\
\hline Austria & 82 & 70 & 184 & 80 & 30 & 110 & 90 & 110 & 8 & 75 \\
Belgium & 115 & 98 & & 108 & 2 & 110 & 85 & 108 & 92 & 33 \\
Denmark & 155 & 100 & & 150 & 20 & 155 & 110 & 110 & 62 & 116 \\
Finland & 120 & 78 & & 110 & & 83 & 100 & 100 & 85 & 41 \\
France & 85 & 72 & & 80 & 40 & 70 & 120 & 80 & 47 \\
Germany & 165 & 150 & 150 & 170 & 25 & 140 & 145 & 165 & 94 & 131 \\
Greece & 150 & 78 & & 100 & & 120 & 100 & 140 & 118 & 18 \\
Ireland & 80 & 120 & 170 & 155 & 150 & 35 & 145 & 45 & 52 & 59 \\
Italy & 70 & 75 & 190 & & 40 & 200 & 140 & 170 & 180 & 64 \\
Netherlands & 160 & 110 & & 150 & & 120 & 180 & 49 \\
Portugal & 190 & 85 & 44 & 180 & 20 & 168 & 108 & 125 & 30 & 38 \\
Spain & 95 & 90 & 225 & 109 & 9 & 142 & 178 & 205 & 27 & 75 \\
Sweden & 80 & 60 & 160 & 100 & 5 & 100 & 150 & 120 & 80 & 73 \\
United Kingdom & 183 & 118 & & 185 & 5 & 155 & 100 & 125 & 75 & 30 \\
\hline EU15 & 92 & 91 & 101 & 158 & 14 & 129 & 136 & 109 & 54 & 69 \\
\hline
\end{tabular}

nitrogen excretion, acreages for the cultivation of the crops, and their respective productivity).

- While the individual simulation units allow for consistent integration of biophysical impact vectors in economic land use optimization models, the HSMUs are an integral part of both the economic and the biophysical model. This allows us to intimately link both modelling approaches, which is a prerequisite for efficient environmental policy impact assessment.

\subsection{Land use map}

The legend of the CORINE Land Cover map contains eleven pure or mixed agricultural classes. Interpretation, particularly of the mixed classes such as "complex cultivation patterns", is very different for different regions in Europe. The typical land-use mix for this class differs largely between countries. Complex cultivation patterns, according to the definition (Bossard et al., 2000), consist of a "juxtaposition of small parcels of diverse annual crops, pasture and/or permanent crops" with built-up parcels covering less than $30 \%$. In Spain, for example, permanent crops and cereals account for $35 \%$ and $15 \%$ of the area covered by this class, respectively, while in Germany cereals have a large share (40\%) and permanent crops are insignificant. In addition, comparisons of CORINE with detailed statistics resulted in large disagreements (Schmit et al., 2006). At the European scale a simple downscaling procedure on the basis of CORINE would therefore lead to biased estimation of land use shares.

Hence, from a conceptual point of view, the procedure described in Sect. 2.3 can be interpreted as a "calibration" of the CORINE Land Cover/Use map, giving more detailed information on the share of individual crops in mixed and het- erogeneous classes (e.g. non-irrigated arable land and complex cultivation pattern, respectively), but also on the share of non-agricultural area for each class. An overview of crop associations in the main CORINE land cover classes covering about $80 \%$ of the UAAR in EU15 is given in Table 5. Grassland covers $14 \%$ of the surface area of Europe and is the most important agricultural land use for most countries with shares of up to $75 \%$ of the UAAR (Ireland).

We compared the results of our methodology by disaggregating NUTS 2 data from the agricultural census of the European Union, the FSS (FSS2000, European Commission, 2003b) and calculating the share of mis-classified agricultural area for regions where data were available at a more detailed level (NUTS 3). The validation procedure is described in detail in the appendix. We obtained an area weighted mean error of $\sim 12.2 \%$ for Europe. Compared with a "no-disaggregation" scenario, we achieved a reduction of the error by a factor of two.

With the exception of non-irrigated arable land, grassland occupies the largest share of the area of the mixed land cover classes. The correspondence is highest (92\%) for the class "natural grassland". For other pure land cover classes, our model predicts high correspondence with CORINE, i.e. $78 \%$ for rice fields and $81 \%$ for olive grows. This makes it even more astonishing that in regions with a high percentage of misclassified area, grassland often accounts for a significant part of the errors. This suggests that misclassification errors might not only be a consequence of a poor dis-aggregation procedure but also a result of inconsistent data sources. Generally grassland area tends to be larger in the FSS statistics than in the CORINE land cover map (Grizzetti et al., 2007). For example, the CORINE land cover map reports about 2 Mha "Pasture" and "Natural Grassland" in Spain while the 
FSS reports about 9 Mha of Grassland. Nonetheless the disaggregation is a significant improvement compared to the assumption of identical cropping patterns within each NUTS 2 region. A detailed analysis for Belgium (Schmit et al., 2006) found low reliability for grassland in CORINE as less than half of the pixels that are classified as grassland in CORINE corresponded to grassland pixels in the reference map. Even worse, only a little more than $10 \%$ of the grassland in the reference map was correctly represented by CORINE.

Very rarely, single crops are considered in a model exercise or in other applications. Usually the crops are grouped according to their physical similarity or their analogous agricultural practices. If we consider only crop groups (cereals, fallow land, rice and oilseeds, industrial crops, permanent crops and grassland and fodder), some of the distribution errors level out as, within these groups, the site condition requirements of the plants are sometimes very similar and cannot be easily distinguished by the model. For countries included in the calculation, the dis-aggregation error decreases from $12 \%$ for individual crops to $8 \%$ for crop groups. The error for very coarse crop classes (arable crops, permanent crops and grassland and fodder) is still lower (6.2\%), and $3.4 \%$ of the total UAAR was attributed to the wrong NUTS 3 regions.

\subsection{Input data}

\subsubsection{Fertilizer/manure input}

In the majority of the cases, the nitrogen application rates from CAPRI yielded plausible results when compared to crop removals, especially in the case of mineral application rates where at least average national rates for certain crops or crop groups could be used in the estimation process. If we compare the mineral application rates for individual crops and countries with the information obtained from the International Fertilizer Industry Association (FAO/IFA/IFDC/IPI/PPI, 2002) we find considerable differences (Table 6). The reason can be found in our methodology that links total nitrogen application to nitrogen uptake by plants. This in turn is available from statistical sources. Our approach tries to minimize both the deviation from the IFAapplication rates of mineral fertilizer nitrogen and the share of nitrogen obtained from manure, taking into consideration the availability of manure nitrogen in the region. The IFA estimates are the result of a negotiation procedure between different institutions and are based on information obtained from questionnaires to national administration and industry representatives (FAO/IFA/IFDC/IPI/PPI, 2002). As they ignore the regional effect of the distribution of the animals, small deviations from the IFA estimates might occur. These deviations depend on the location of the cropland in relation to the stocking density of animals and the soil quality in the region.

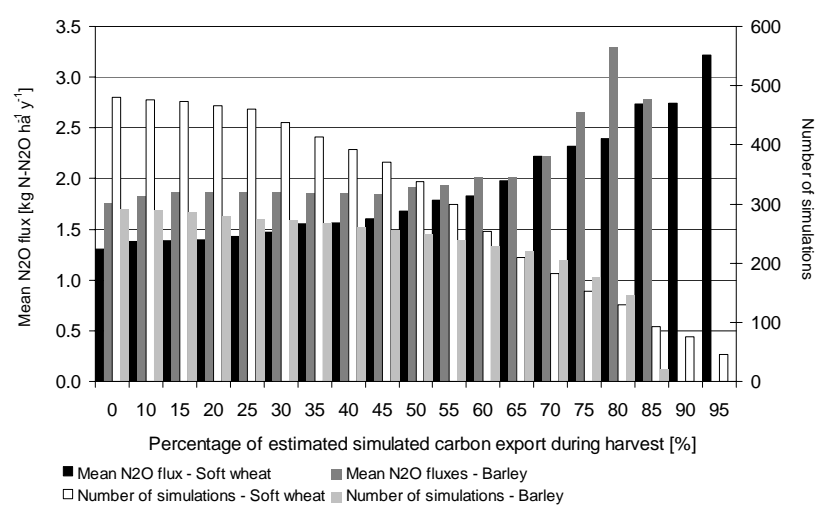

Fig. 7. Number of simulations yielding at least a given percentage of estimated plant carbon uptake for soft wheat and barley (lightcoloured columns, right axis), and mean $\mathrm{N}_{2} \mathrm{O}$ fluxes estimated on the respective sub-samples (dark coloured columns, left axis).

\subsubsection{Yield}

Our approach aims to match as far as possible the uptake of carbon and nitrogen simulated with the biophysical model DNDC with the available yield statistics at the regional level and the estimated information (yield downscaled to the spatial calculation unit). Differences are due to stress situations that tend to reduce plant growth in the simulation model. As an example, Fig. 7 shows the number of simulations and the corresponding mean $\mathrm{N}_{2} \mathrm{O}$ fluxes, if only simulations yielding a minimum of the carbon export estimated with CAPRI are taken into account. The figure compares two cereals, soft wheat and barley, which differ with respect to simulated carbon export and $\mathrm{N}_{2} \mathrm{O}$ fluxes. Soft wheat has stricter requirements on environmental conditions than barley. Due to its lower capability to store humidity, it has a higher demand on summer precipitation. Therefore, stress is much higher for soft wheat with a lower average relative yield. While the median $\mathrm{N}_{2} \mathrm{O}$ flux of all simulations with soft wheat cultivation is only $1.3 \mathrm{~kg} \mathrm{~N}-\mathrm{N}_{2} \mathrm{O} \mathrm{ha}^{-1} \mathrm{y}^{-1}$, it increases continuously if plant uptake of nitrogen gets closer to the optimum. For the last 50 simulations (approximately 7\%) where at least 95\% of nitrogen export was simulated, we obtain an $\mathrm{N}_{2} \mathrm{O}$ flux of $3.2 \mathrm{~kg} \mathrm{~N}-\mathrm{N}_{2} \mathrm{O} \mathrm{ha}^{-1} \mathrm{y}^{-1}$. This is similar to the emissions from barley for non-limited simulations, while the overall median for barley with $1.8 \mathrm{~kg} \mathrm{~N}-\mathrm{N}_{2} \mathrm{Oha}^{-1} \mathrm{y}^{-1}$ is higher than that of soft wheat.

Thus, we observe that (i) environmental conditions play a major role both in the choices of the farmers and what they are going to cultivate; in DNDC, penalties for stress conditions are smaller than in CAPRI and decreases in expected yield are thus strongly limited by fertilizer input; (ii) highest emissions occur on high-productivity sites, expressed relative to the cultivated area or production unit. 


\subsubsection{Soil map}

The effort invested into the development of an agricultural land use map of high resolution is justified by the need to spatially match agricultural activities with environmental conditions, mainly soil properties, which have been identified to be the major reason for high uncertainty. These efforts are currently not adequately matched by the quality of the soil map. A reason for concern arises in particular from two characteristics of the data used, i.e. (i) soil types are not directly mapped, and (ii) the derivation of soil properties in the raster maps is done using fixed land use information.

The spatial components of the soil database of Europe, the so-called SMUs corresponding to a soil type association, comprise a varying number of soil types with unknown spatial location and a defined share of the SMU area. However, variations in soil organic carbon or other attributes within an SMU are accounted for by including information on land use (CORINE Land Cover 1990 map), climate and Soil Typological Unit (STU). Inconsistencies might arise, particularly if the land use estimated in the present study differs largely from the land use that was used in the derivation of the soil characteristics. We tried to account for this by "filtering" out HSMUs with a high share of forest area in CORINE 1990 (European Topic Centre on Terrestrial Environment, 2000) as compared to the land use shares estimated in our approach. Nevertheless, we observed a very high average soil organic carbon content in Finland, where only $2764 \mathrm{~km}^{2}$ of agricultural area is estimated to be cultivated on organic soils (Statistics Finland, 2005) corresponding to approximately $22 \%$ of the agricultural area in our database. This could result in uncertainties. Based on the decomposition and denitrification processes built in DNDC, cultivated organic soils under humid climate conditions can have high rates of $\mathrm{N}_{2} \mathrm{O}$ as well as dinitrogen $\left(\mathrm{N}_{2}\right)$ emissions. Therefore, any overestimation on the combination of agricultural area with organic soil could overestimate $\mathrm{N}_{2}$ losses and $\mathrm{N}_{2} \mathrm{O}$ emissions. We estimate significant agricultural activities on highly organic soils (>100 $\mathrm{tC} \mathrm{ha}^{-1}$ ) in Finland (barley and oats), Sweden (barley and fodder production), Belgium (maize) and Netherlands (maize and softwheat), so that the simulated denitrification losses (see Table 4) have a higher uncertainty for those countries.

In the present study we obtained realistic soil initialization by conducting a 98 year spin-up run. Nevertheless it will be of highest priority to incorporate the estimation of soil characteristics into the land use share model to refine the available soil information.

\subsection{General discussion}

It is frequently recognized that the impact of society on the environment is costly and needs to be considered when policy impact analyses are performed. Supporting tools are required to answer two primary questions: "what is the impact of a certain policy pathway?" and "how much does it cost to reduce this impact?" Prominent integrated modelling frameworks include the Integrated Model to Assess the Global Environment (IMAGE, Bouwman et al., 2006) and the RAINS model (e.g. Höglund-Isaksson et al., 2006). Integrated modelling systems link socio-economic analyses with environmental assessment, usually working with a multi-sectoral approach. Due to the large number of variables they have to deal with, they are based on simple relationships or empirical functions. On the other hand, sectoral "integrated models" are able to simulate both socio-economy and environment of a single sector with great detail and are thus able to deliver targeted policy impact assessments.

For example Schneider et al. (2007) present an analysis of mitigation options in USA agriculture and forestry, with a biophysical model predicting GHG emission coefficients and carbon stock changes for various management options.

Another example of such a sectoral integrated modelling framework is the EFEM-DNDC system described by Neufeldt et al. (2006). In their system, the economic farm emission model EFEM is linked to the biophysical model DNDC via crop acreage and fertilizer intensity estimates for one of eight different regional groups in BadenWürttemberg, Germany, which are composed of several municipalities with similar environmental conditions and typical production systems. The downscaling of this information to the modelling units was done on the basis of the CORINE land cover map, including a correction factor to account for differences in agricultural area between the statistics and CORINE. Our approach is very similar to the EFEM-DNDC approach. The main differences are (i) a more "elaborate" approach for downscaling, and (ii) a closer link between both modelling systems, as nitrogen application rates are adapted to the individual conditions of the spatial calculation units.

We regard both features as an essential element for an agricultural integrated modelling framework, particularly for a large-scale application as in the present study. One of the most important features of an integrated modelling framework is a consistent flow of nutrients in the various modules. The approach described above is designed to reach maximum consistency both in term of scale (scale-consistent downscaling from national and regional statistics to a grid based on $1 \mathrm{~km} \times 1 \mathrm{~km}$ pixels) and in terms of mass-flow through agricultural sub-systems.

\section{Conclusions}

We presented an approach that links an economic model for agriculture with a process-based simulation model for arable soils for Europe. The procedure developed involves two steps. The first step consists in the generation of spatially explicit information at the level of clustered $1-\mathrm{km}$ grid cells on land use, animal density, and agricultural input parameter in the framework of the economic model CAPRI. In the 
second step these data are used to drive the process-based model DNDC to calculate soil nitrogen and carbon turnover.

This procedure described has three major advantages:

- The approach is based on a systematic and consistent integration of geo-referenced agricultural statistics and agricultural management practices. It maintains scale consistency with the regional statistics of the economic model with which the spatial calculation units (HSMUs) are linked (e.g. for simulations with the official EUROSTAT statistics). Nitrogen application per crop reflects observed agricultural practices while taking local conditions (soil, stocking densities, potential yields) into account.

- Simulations with the biophysical model are performed on units containing the full information of the economic model (thematic consistency), while minimizing the computational cost/benefit ratio. Through the inherent linkage between the economic and the bio-physical model, both ex-post and ex-ante analyses become possible.

- The approach is very flexible and can be used to create for each model a different but consistent data set which is tailored to the model's needs.

The linkage between these two models extends thematically to a spatially explicit land use map under the current economic situation and a consistent calculation of agricultural input parameters (manure production and mineral and manure nitrogen application) and yield. It extends geographically to all Member States of the European Union. The combination - sub-continental coverage on one hand and detailed and consistent assessment of land use and agricultural management on the other hand - distinguishes our approach from other studies (e.g. Kesik et al., 2005; Neufeld et al., 2006; Schröter et al., 2005; Sleutel et al., 2006).

The linkage and consistency with national and international statistics regarding land use, crop production and nitrogen application is especially important in view of potential future applications for reporting requirements (such as the reporting under the United Nations Framework Convention on Climate Change - UNFCCC).

We emphasize that the results, in terms of estimated nitrogen fluxes, must still be considered as illustrative, as possibilities for improvements have been identified and will be the focus of future work. However, these reservations must be looked at in relation with the overall ambition of our study, as the problems identified are common to most studies dealing with regional to continental assessment of soil processes. Nevertheless, we were already able to highlight interdependencies between farmer's choices of land uses and the environmental impact of different cultivation systems.

\section{Appendix A}

\section{Validation of the land use and livestock density maps}

\section{A1 A Validation of the land use maps}

Error assessment analyses of the agricultural land use maps have been performed both at the regional scale, using districtto regional-scale statistics from an agricultural census of the year 2000 covering the EU15 Member States, and at the local scale, using commune-level statistics of the Lombardia region in Italy and in Netherlands.

The economic model CAPRI uses statistical information for agricultural land use for NUTS 2 regions. Therefore the initial distribution of the different crops to the individual HSMUs was performed based on NUTS 2 agricultural statistics.

These results were compared with the data from the agricultural census of the European Union, the FSS (FSS2000, European Commission, 2003b). For some European regions, land use statistics from the FSS2000 are available at a lower administrative level, i.e. NUTS 3. Within the area where both data sets were available (see Fig. A1) the NUTS 2 regions are subdivided into a minimum of 2 and a maximum of 10 NUTS 3 regions. For the comparison, distribution results at the HSMU level were aggregated to the NUTS 3 level and compared with the FSS2000 statistics as out-ofsample data. For each individual crop the difference between the crop area given by FSS2000 and the area of the dis-aggregation result was calculated. All positive area differences were summed up for all crops and expressed as percentage of the total NUTS 2 agricultural area. In this way we obtained the share of misclassified agricultural area in a NUTS 2 region (Fig. A1) for all regions where FSS2000 data at NUTS 3 level were available. In addition, the pie charts in Fig. A1 depict the contribution of each crop to the total error.

The misclassified agricultural area within NUTS 2 regions ranges between 2 and 35\%. We obtained an area-weighted mean error of $\sim 12.2 \%$ for Europe. With the developed disaggregation procedure very good results $(2-15 \%$ misclassified area) have been obtained for United Kingdom, Ireland, France and southern Spain. The errors are slightly higher in northern/central Spain and Portugal. For southeastern Italy, Greece and some regions in Sweden and Finland errors of about 25-35\% occur. The higher errors in Sweden and Finland can be explained by the very small agricultural area which has to be located in quite large HSMUs. High errors can be also a consequence of inaccuracies and inconsistencies in the input data for the dis-aggregation (CORINE land use/cover, LUCAS survey, agricultural statistics, etc.).

Error assessments of the agricultural land use maps have also been performed at the local scale, using 2003 commune-level statistics of the Lombardia region in Italy (ERSAF, 2005) and Netherlands. We present the former results here. 


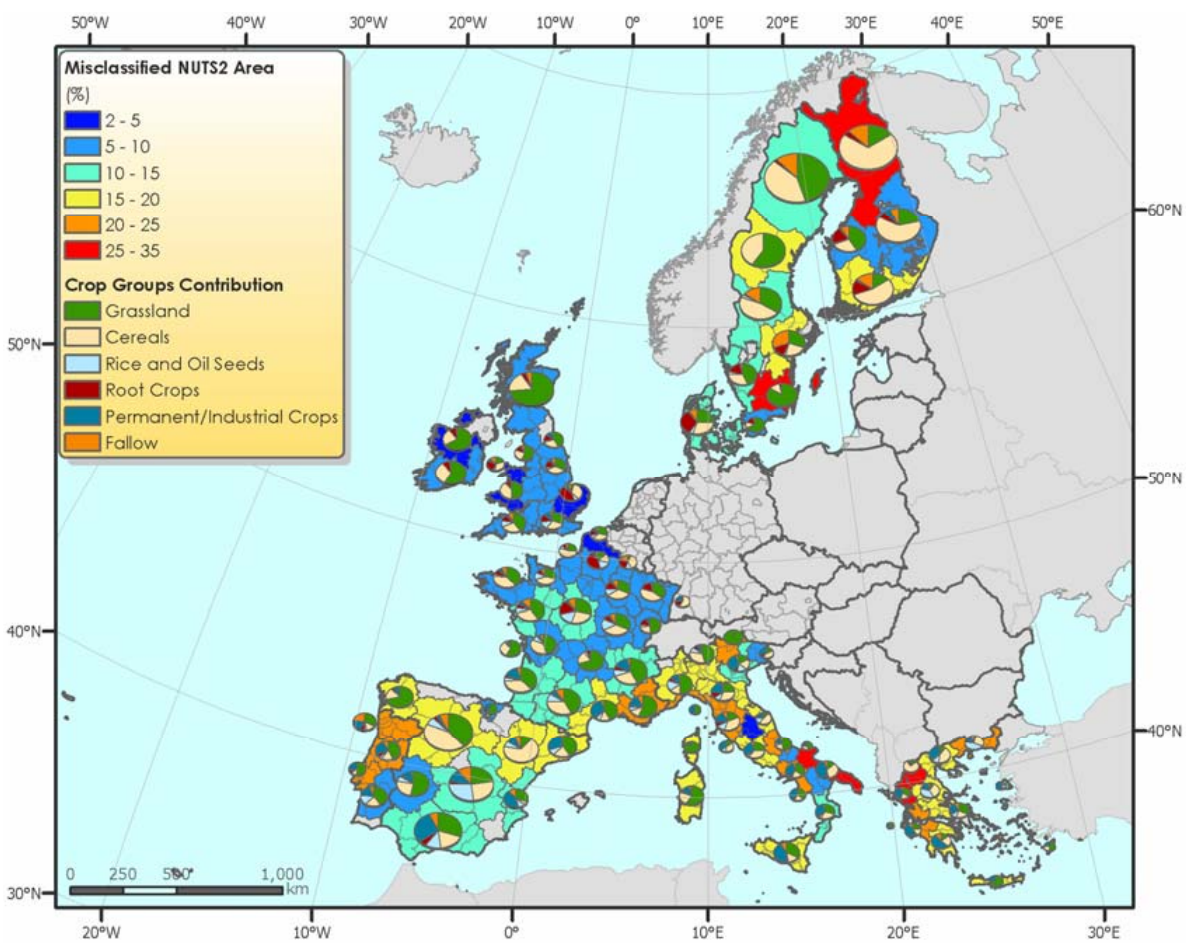

Fig. A1. Percentage of misclassified areas in validated NUTS 2 regions after dis-aggregation. The pies show the contribution of different crop groups to the total error in the region (Cereals: soft wheat, durum wheat, barley, rye, oats, maize, other cereal; Fallow: fallow land; Rice and Oil Seeds: rice, sunflower, soya, texture crops, pulses, other crops; Root Crops: potatoes, sugar beet, root crops, rape, nurseries; Permanent/Industrial Crops: tobacco, other industrial, vegetables, flowers, citrus trees, fruit trees, olive trees, vineyards; Grassland: grassland, fodder production). Note that the size of the pie is related to the area of the NUTS 2 region for visualization purposes only.

For the Lombardia region, we compared the rice and maize distribution in 190 communes with the results of the dis-aggregation. For illustration, Fig. A2 shows the dis-aggregation result $(1 \mathrm{~km} \times 1 \mathrm{~km}$ grid resolution $)$ and the maize fields based on data for a set of communes (ERSAF, 2005). The maize pattern (light brown areas) indicating a maize share of $30 \%$ from the dis-aggregation result corresponds with the main maize field distribution based on ERSAF. But looking at the scatter plot (Fig. A3a) comparing ERSAF and dis-aggreation data for maize in all 190 communes, it can be seen that generally the dis-aggregation blurs the distribution that is more distinct in reality. To interpret this comparison, however, one has to keep in mind that in this region the areas of the single communes are close to the mean HSMU area and sometimes even larger. Our approach does not allow distributing crop area below the HSMU level and therefore some discrepancies are unavoidable. Thus, we reach herewith the maximum level of detail that can be considered. Furthermore maize is a crop that has no single corresponding CORINE land cover class in which it occurs but is distributed over a range of classes. The contrary holds for rice as a separate rice fields class is given in CORINE thus the dis-aggregation result for rice (Fig. A3b) corresponds closely to the communal data.

We learned from this comparison that a large portion of the error was introduced when resampling the original
CORINE land cover map at the resolution of $100 \mathrm{~m}$ into the $1 \mathrm{~km} \times 1 \mathrm{~km}$ pixels. This was necessary because of computing resources, as CORINE was used for the delineation of the HSMU. We expect to improve the accuracy of the disaggregation in future versions, if the land cover map is used at the original resolution as an attribute of the HSMUs.

\section{Appendix B}

\section{Validation of the livestock density map}

The data set resulting from the distribution algorithm of animal activities was validated using out-of-sample data available for France at the level of 36000 communes from the FSS. The individual herd sizes shown per commune were aggregated to livestock units. The results obtained for about 24000 pixel clusters for France were averaged per commune and the absolute error in the stocking densities was calculated. A result of 0.5 , for example, indicates that the area weighted average livestock density of the HSMU polygons intersecting the polygon of the commune is 0.5 livestock units per ha higher then the data reported in the French FSS. The resulting map is shown in Fig. B1a. The errors are classified in $5 \%$ quantiles so that, as shown in the legend, in $90 \%$ of the communes the error in estimating the stocking density is 


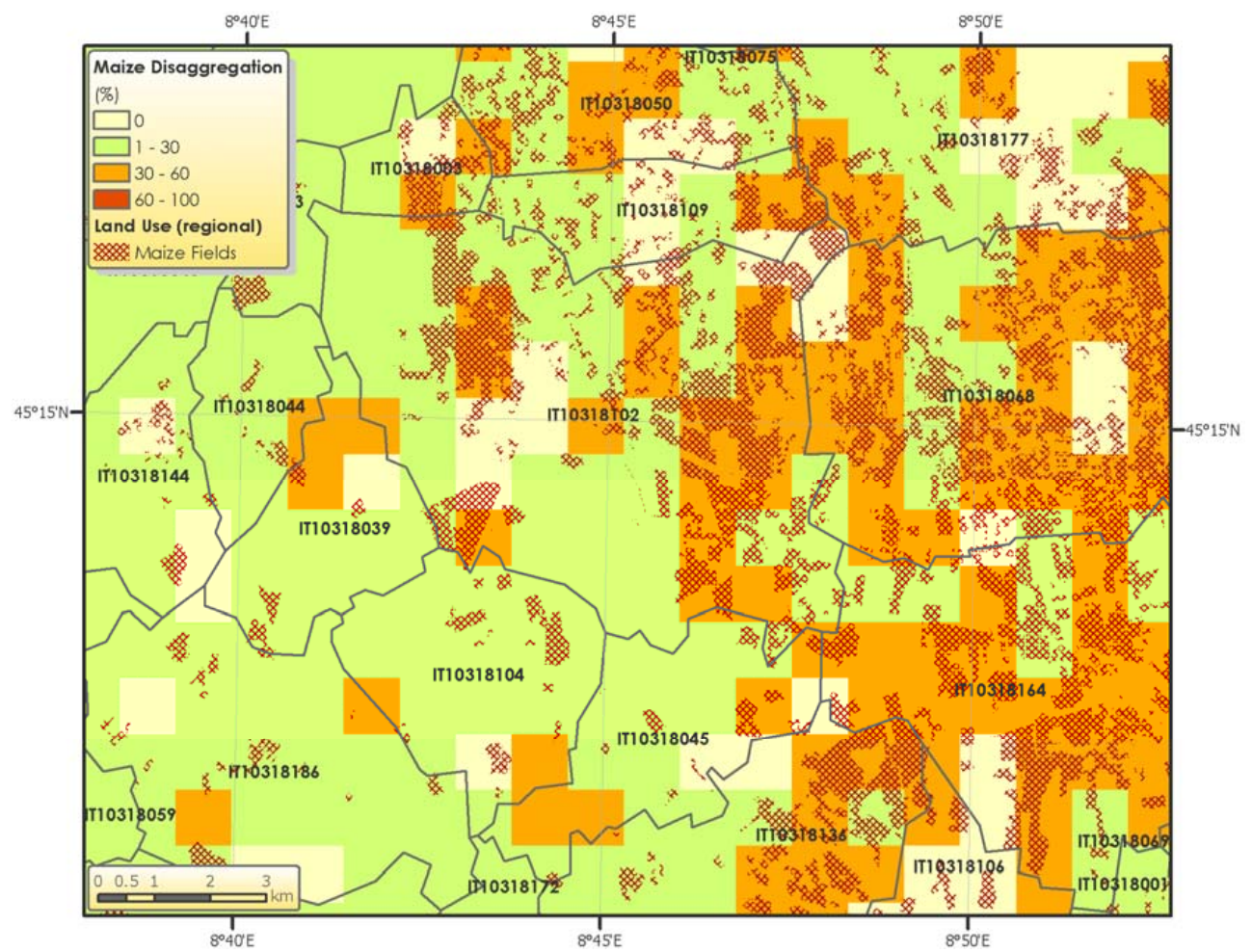

Fig. A2. Dis-aggregation result for maize and maize fields given in the ERSAF (2005) agricultural land use map. The grey borders outline individual communes.

a)

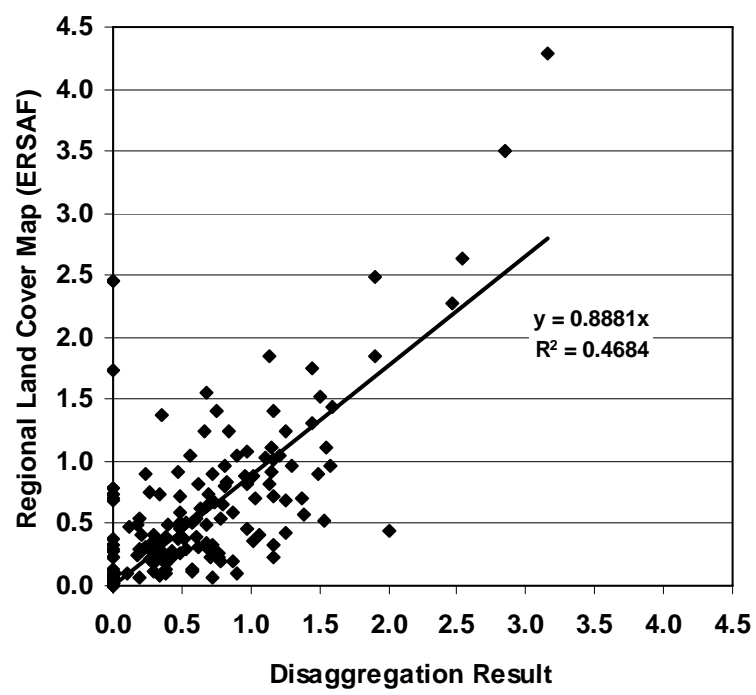

b)

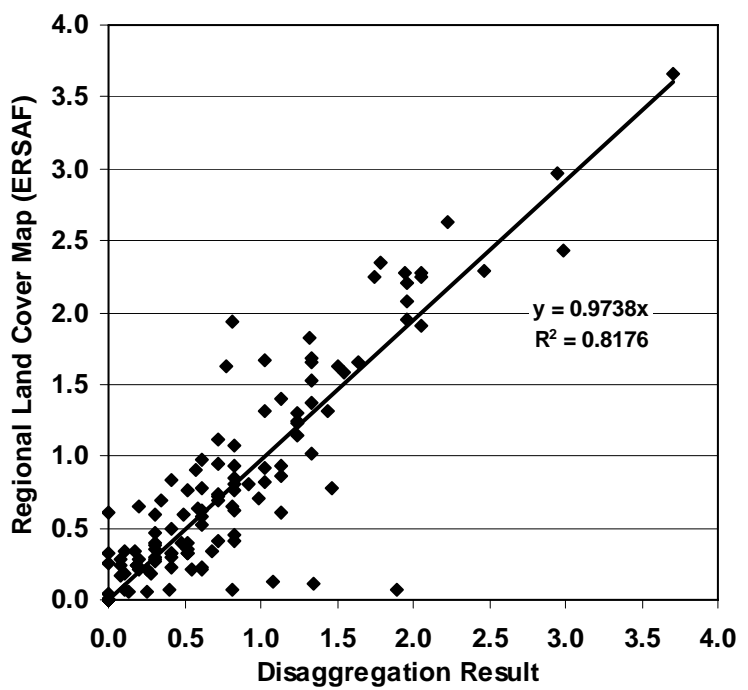

Fig. A3. Comparison of communal data (ERSAF, 2005) and dis-aggregation results in the Italian Pavia province (Mortara, IT208) for the 190 single communes. Maize (a) and rice (b) distribution as percentage of the total maize (rice) area within the province.

between -0.46 or $+0.43 \mathrm{LU} \mathrm{ha}^{-1}$. In $80 \%$ of the communes the errors is between -0.28 and $+0.31 \mathrm{LU} \mathrm{ha}^{-1}$. Those errors were compared with estimates by commune, using the NUTS 3 average livestock density, with errors shown in Fig. A4b.
Those livestock densities are the boundary data to which the results of the HSMUs in that NUTS 3 region had been consolidated. It can be seen that the statistical estimator for the livestock densities yields results which are somewhat similar 

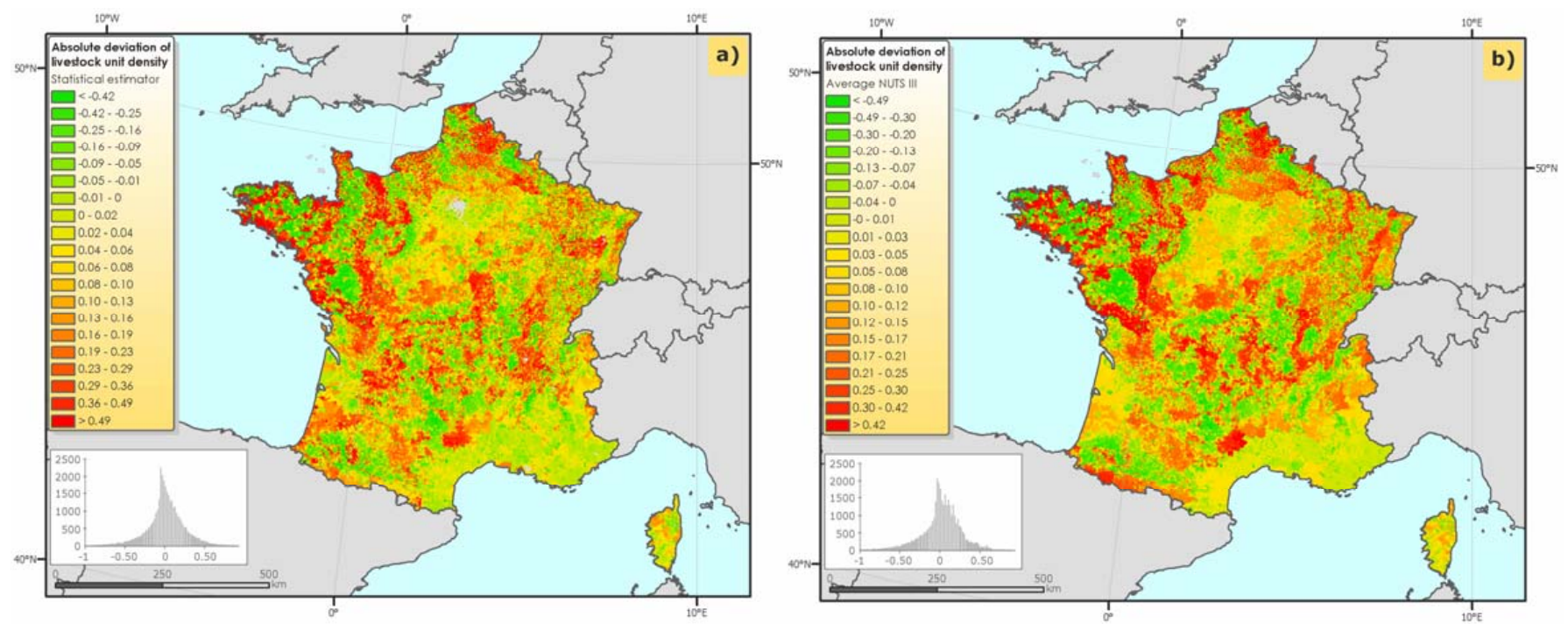

Fig. B1. Error distribution of the distribution algorithm of animal activities, expressed in absolute deviation of the livestock unit density from activity level at commune level for (a) the statistical estimator and (b) average NUTS 3 livestock densities.

to using NUTS 3 averages (see Fig. B1b). However, when comparing the quantiles of the error distribution, it is obvious that the error distribution of estimator is more peaked, as can be seen also from the distribution diagrams shown in the figures, i.e., the number of communes with a small difference between the observed and the estimated stocking densities is higher for the estimates than for average NUTS 3 livestock densities. Furthermore, the map with the errors from using the NUTS 3 livestock densities shows a sharper clustering of errors in space. That observation is important as organic fertilizer applications for a specific HSMU are generated inter alia from a distance- and size-weighted average of surrounding HSMUs. When errors are clustered in space, averaging over HSMUs will not reduce errors, whereas with a high variance of errors in space, especially if HSMUs with under- and over-estimated stocking densities are near to each other, averaging will reduce the overall error.

Acknowledgements. This work was partly funded by the European Commission in the CAPRI-DynaSpat project (SSPE-CT-2004501981) in the sixth framework program. We thank S. Frolking of University of New Hampshire for his editing with the manuscript. We are grateful for detailed proof-reading by M. Wattenbach and three anonymous referees.

Edited by: F. X. Meixner

\section{References}

Annoni, A.: European Reference Grids, Proposal for a European Grid Coding System, Proceedings and Recommendations of the European Reference Grids Workshop, Ispra, 27-29 October 2003, EUR Report 21494 EN: European Communities, 2005.
Anselin, L., Florax, R. J. G. M., and Rey, S. J.: Advances in Spatial Econometrics, Springer Verlag, Berlin, 2004.

Bareth, G., Heincke, M., and Glatzel, S.: Soil-land-use-system approach to estimate nitrous oxide emissions from agricultural soils, Nutr. Cycl. Agroecosys., 60, 219-234, 2001.

Bossard, M., Feranec, J., and Otahel, J.: CORINE land cover technical guide - Addendum 2000, Technical Report No. 40, Copenhagen: European Environment Agency, 2000.

Bouraoui, F. and Aloe, A.: European Agrochemicals Geospatial Loss Estimator: Model Development and Applications, European Commission, Joint Research Centre, Institute for Environment and Sustainability, ISBN 978-92-79-05053-4, p. 107, 2007.

Bouwman, A. F., Kram, T., and Klein Goldewijk, K.: Integrated modelling of global environmental change, An overview of IMAGE 2.4, Bilthoven, The Netherlands: Netherlands Environmental Assessment Agency (MNP), 2006.

Britz, W.: CAPRI Modelling System Documentation. Common Agricultural Policy Regional Impact Analysis p. Bonn, Germany: available at: http://www.agp.uni-bonn.de/agpo/rsrch/ capri/capri-documentation.pdf, 2005.

Britz, W., Wieck, C., and Jansson, T.: National Framework of the CAPRI Data base: The CoCo-Module, Working paper 02-04, CAPRI Project, Institute for Agricultural Policy, Bonn, 2002.

Brown, L., Syed, B., Jarvis, S. C., Sneath, R. W., Phillips, R. L., Goulding, K. W. T., and Li, C.: Development and application of a mechanistic model to estimate emission of nitrous oixde from UK agriculture, Atmos. Environ., 36, 917-928, 2002.

Butterbach-Bahl, K., Kesik, M., Miehle, P., Papen, H., and Li, C.: Quantifying the regional source strength of N-trace gases across agricultural and forest ecosystems with process based models, Plant Soil, 260, 311-329, 2004.

CCM 250 DEM: EuroLandscape/Agri-Environment Catchment Characterisation and Modellig Activity, Land Management Unit, Institute for Environment and Sustain-ability, EC-Joint Research Centre, 250 Meter DEM, compiled on the basis of data acquired 
from data providers and national mapping agencies over Europe for internal use, 2004.

Commission of the European Communities: Proposal for a directive of the European Parliament and of the Council establishing an infrastructure for spatial information in the Community (INSPIRE), COM(2004) 516 final, 2004.

Del Grosso, S. J., Mosier, A. R., Parton, W. J., and Ojima, D. S.: DAYCENT model analysis of past and contemporary soil $\mathrm{N}_{2} \mathrm{O}$ and net greenhouse gas flux for major crops in the USA, Soil Till Res., 83, 9-24, 2005.

EC: On the establishment of a common classification of territorial units for statistics (NUTS), Official Journal of the European Union, L 154/1, 2003.

EEA: Annual European Community greenhouse gas inventory 1990-2004 and inventory report 2006, Submission to the UNFCCC secretariat, European Environment Agency, 2006.

EMEP: EMEP measurement database (Available online from http: //www.emep.int/), The Co-operative Programme for the Monitoring and Evaluation of the Long-Range Transmission of Air Pollutants in Europe, 2001.

EMEP/CORINAIR: Joint EMEP/CORINAIR Emission Inventory Guidebook - 3rd edition October 2002, updated 2003, http: //tfeip-secretariat.org/unece.htm, 2003.

ERSAF: Progetto "Cartografie investimenti su basi dati SIARL" Utilizzo del suolo annate agrarie 2003 e 2004, Ente Regionale per i Servizi all'Agricoltura e alle Foreste, Regione LombardiaAgricoltura, 2005.

European Commission: The Lucas survey. European statisticians monitor territory, Theme 5: Agriculture and fisheries, Office for Official Publications of the European Communities, Luxembourg, 2003, 24 pp, 2003a.

European Commission: Farm Structure 1999/2000 Survey. Theme 5 Agriculture and Fisheries, Office for Official Publications of the European Communities, Luxembourg, 2003, 2003 b.

European Commission: European Soil Database (version V2.0), CD-ROM EUR 19945 EN, March 2004, European Commission, Directorate General Joint Research Centre, Institute for Environment and Sustainability, 2004.

European Topic Centre on Terrestrial Environment: CORINE land cover database (Version 12/2000), 2000.

FAO/IFA/IFDC/IPI/PPI: Fertilizer use by crop, Fifth edition, Rome: FAO - Food and Agriculture Organization of the United Nations, 2002.

Genovese, G., Baruth, B., Royer, A., and Burger, A.: Crop and yield monitoring activities - MARS STAT action of the European Commission, Geoinformatics, 10, 20-22, 2007.

Grant, B., Smith, W. N., Desjardins, R., Lemke, R., and Li, C.: Estimated $\mathrm{N}_{2} \mathrm{O}$ and $\mathrm{CO}_{2}$ Emissions as Influenced by Agricultural Practices in Canada, Clim. Change, 65, 315-332, 2004.

Grizzetti, B., Bouraoui, F., and Aloe, A.: Spatialised European Nutrien Balance, EUR 22692 EN, Luxembourg: Office for Official Publications of the European Communities, 2007.

Hiederer, R., Jones, B., and Montanarella, L..: European Soil Raster Maps (1 km by $1 \mathrm{~km}$ ) for Top-soil Organic Carbon Content, Texture, Depth to Rock, Soil Structure, Packing Density, Base Saturation, Cation exchange, Developed under the EC-JRC-Action 2132: Monitoring the state of European soils (MOSES), 2003.

Höglund-Isaksson, L., Winiwarter, W., Klimont, Z., and Bertok, I.: Emission scenarios for methane and nitrous oxides from the agri- cultural sector in the EU-25, IIASA Interim Report IR-06-019, Laxenburg, Austria: International Institute for Applied Systems Analysis, 2006.

IPCC: Revised 1996 IPCC Guidelines for National Greenhouse Gas Inventories, edited by: Houghton, J. T., Meira Filho, L. G., Lim, B., et al., Paris, France, IPCC/OECD/IEA, 1997.

IPCC: Good Practice Guidance and Uncertainty Management in National Greenhouse Gas Inventories, edited by: Penman, J., Kruger, D., Galbally, I., et al., Hayama, Japan, IPCC/OECD/IEA/IGES, 2000.

IPCC: IPCC Guidelines for National Greenhouse Gas Inventories, Prepared by the National Greenhouse Gas Inventories Programme, edited by: Eggleston, H. S., Buendia, L., Miwa, K., et al., IGES, Japan, 2006.

Jones, R. J. A., Hiederer, R., Rusco, E., and Montanarella, L.: Estimating organic carbon in the soils of Europe for policy support, Eur. J. Soil Sci., 56, 655-671, 2005.

Kempen, M., Heckelei, T., Britz, W., Leip, A., and Koeble, R.: Computation of a European Agricultural Land Use Map - Statistical Approach and Validation. Technical Paper, Institute for Food and Resource Economics, Bonn, 2007. (available at:http: //www.ilr1.uni-bonn.de/agpo/rsrch/dynaspat/publicat.htm)

Kesik, M., Ambus, P., Baritz, R., Brüggemann, N., ButterbachBahl, K., Damm, M., Duyzer, J. H., Horvath, L., Kiese, R., Kitzler, B., Leip, A., Li, C., Pihlatie, M., Pilegaard, K., Seufert, G., Simpson, D., Skiba, U., Smiatek, G., Vesala, T., and Zechmeister-Boltenstern, S.: Inventory of $\mathrm{N}_{2} \mathrm{O}$ and $\mathrm{NO}$ emissions from European forest soils, Biogeosci., 2, 353-357, 2005.

Leip, A.: Executive Summary and Recommendations, in: $\mathrm{N}_{2} \mathrm{O}$ emissions from agriculture, edited by: Leip, A., Report on the expert meeting on "improving the quality for greenhouse gas emission inventories for category 4D”, Joint Research Centre, 21-22 October 2004, Ispra., Vol. EUR 21675. Luxembourg: Office for Official Publication of the European Communities, p. 155-160, 2005.

Lettens, S., Orshoven, J., Wesemael, B., Muys, B., and Perrin, D.: Soil organic carbon changes in landscape units of Belgium between 1960 and 2000 with reference to 1990, Glob. Change Biol., 11, 2128-2140, 2005.

Li, C.: Modeling trace gas emissions from agricultural ecosystems, Nutr. Cycl. Agroecosyst., 58, 259-276, 2000.

Li, C., Frolking, S., and Frolking, T. A.: Model of nitrous oxide evolution from soil driven by rainfall events: 1 . Model structure and sensitivity, J. Geophys. Res., 97, 9759-9776, 1992.

Li, C., Frolking, S., and Harriss, R.: Modeling carbon biogeochemistry in agricultural soils, Global Biogeochem. Cy., 8, 237-254, 1994.

Li, C., Frolking, S., and Butterbach-Bahl, K.: Carbon sequestration in arable soils is likely to increase nitrous oxide emissions offsetting reductions in climate radiative forcing, Clim. Change, 72, 321-338, 2005.

Li, C., Frolking, S., Moore B, I., Boles, S., Qiu, J., Huang, Y., Salas, W., and Sass, R.: Modeling impacts of farming management alternatives on $\mathrm{CO} 2, \mathrm{CH} 4$, and $\mathrm{N} 2 \mathrm{O}$ emissions: A case study for water management of rice agriculture of China, Global Biogeochem. Cy., 19, doi:10.1029/2004GB002341, 2005.

Li, C., Salas, W., DeAngelo, B., and Rose, S.: Assessing Alternatives for Mitigating Net Greenhouse Gas Emissions and Increasing Yields from Rice Production in China Over the Next Twenty 
Years, J. Environ. Qual., 35, 1554-1565, 2006.

Li, C., Mosier, A. R., Wassmann, R., Cai, Z., Zheng, X., Huang, Y., Tsuruta, H., Boonjawat, J., and Lantin, R. S.: Modeling greenhouse gas emissions from rice-based production systems: Sensitivity and upscaling, Global Biogeochem. Cy., doi:10.1019/2003GB002045, 2004.

Li, C. S., Zhuang, Y. H., Cao, M. Q., Crill, P., Dai, Z. H., Frolking, S., Moore B, III, Salas, W., Song, W. Z., and Wang, X. K.: Comparing a process-based agro-ecosystem model to the IPCC methodology for developing a national inventory of N2O emissions from arable lands in China, Nutr. Cycl. Agroecosyst., 60, 159-175, 2001.

Lilly, A., Ball, B. C., McTaggart, I. P., and Horne, P. L.: Spatial and temporal scaling of nitrous oxide emissions from the field to the regional scale in Scotland, Nutr. Cycl. Agroecosyst., 66, 241-257, 2003.

Liu, Y., Yu, Z., Chen, J., Zhang, F., Doluschitz, R., and Axmacher, J. C.: Changes of soil organic carbon in an intensively cultivated agricultural region: A denitrification-decomposition (DNDC) modelling approach, Sci. Total Environ., 372, 203-214, 2006.

Mulligan, D. T.: Regional modelling of nitrous oxide emissions from fertilised agricultural soils within Europe, $\mathrm{PhD}$ thesis, Bangor: University of Wales, 2006.

Neufeldt, H., Schafer, M., Angenendt, E., Li, C., Kaltschmitt, M., and Zeddies, J.: Disaggregated greenhouse gas emission inventories from agriculture via a coupled economic-ecosystem model, Agriculture, Ecosystems and Environment, 112, 233-240, 2006.

Orlandi, S. and Van der Goot, E.: Technical description of interpolation and processing of meteorological data in CGMS, Available under http://agrifish.jrc.it/marsstat/Crop_Yield_Forecasting/ cgms.htm, European Commission, DG JRC, Agrifish Unit, 2003.

Pathak, H., Li, C., and Wassmann, R.: Greenhouse gas emissions from Indian rice fields: calibration and upscaling using the DNDC model, Biogeoscience, 2, 113-123, 2005.

Roelandt, C., Dendoncker, N., Rounsevell, M., Perrin, D., and Van Wesemael, B.: Projecting future $\mathrm{N}_{2} \mathrm{O}$ emissions from agricultural soils in Belgium, Glob. Change Biol., 12, 1-10, 2006.

Schmid, E., Balkovic, J., Moltchanova, E., Skalsky, R., Poltarska, K., Müller, B., and Bujnovsky, R.: Biophysical process modeling for EU25: concept, data, methods, and results, Final Research Report, 2006.

Schmit, C., Rounsevell, M. D. A., and La Jeunesse, I.: The limitations of spatial land use data in environmental analysis, Environ. Sci. Policy, 9, 174-188, 2006.

Schneider, U. A., McCarl, B. A., and Schmid, E.: Agricultural sector analysis on greenhouse gas mitigation in US agriculture and forestry, Agric. Syst., 94, 128-140, 2007.

Schröter, D., Cramer, W., Leemans, R., Prentice, I. C., Araújo, M. B., Arnell, N. W., Bondeau, A., Bugmann, H., Carter, T. R., Gracia, C. A., Vega-Leinert, A. C. d. 1., Erhard, M., Ewert, F., Glendining, M., House, J. I., Kankaanpää, S., Klein, R. J. T., Lavorel, S., Lindner, M., Metzger, M. J., Meyer, J., Mitchell, T. D., Reginster, I., Rounsevell, M., Sabaté, S., Sitch, S., Smith, B., Smith, J., Smith, P., Sykes, M. T., Thonicke, K., Thuiller, W., Tuck, G., Zaehle, S., and Zierl, B.: Ecosystem Service Supply and Vulnerability to Global Change in Europe, Science, 310, 1333-1337, 2005 .
Siebert, S., Döll, P., Hoogeveen, J., Faures, J.-M., Frenken, K., and Feick, S.: Development and validation of the global map of irrigation areas, Hydrol. Earth Syst. Sci., 9, 535-547, 2005, http://www.hydrol-earth-syst-sci.net/9/535/2005/.

Sleutel, S., De Neve, S., Beheydt, D., Li, C., and Hofman, G.: Regional simulation of long-term organic carbon stock changes in cropland soils using the DNDC model: 1. Large-scale model validation against a spatially explicit data set, Soil Use Manage., 22, 342-351, 2006.

Smith, J., Smith, P., Wattenbach, M., Zaehle, S., Hiederer, R., Jones, R. J. A., Montanarella, L., Rounsevell, M. D. A., Reginster, I., and Ewert, F.: Projected changes in mineral soil carbon of European croplands and grasslands, 1990-2080, Glob. Change Biol., 11, 2141-2152, 2005a.

Smith, P., Andren, O., Karlsson, T., Perala, P., Regina, K., Rounsevell, M., and Wesemael, B.: Carbon sequestration potential in European croplands has been overestimated, Glob. Change Biol., 11, 2153-2163, 2005b.

Soussana, J. F., Saletes, S., Smith, P., Schils, R. L. M., and Ogle, S. M.: Greenhouse Gas Emissions from European Grasslands, Specific Study 3, CarboEurope-GHG Concerted Action, 2004.

Statistical Office of the European Communities (EUROSTAT): The Geographic Information System of the European Commission (GISCO) reference database: Version: 07/2003, Brussels, 2003.

Statistics Finland: Greenhouse gas emissions in Finland 1990 2003. National Inventory Report to the UNFCCC, 15th April 2005, 2005.

Tang, H., Qiu, J., Van Ranst, E., and Li, C.: Estimations of soil organic carbon storage in cropland of China based on DNDC model, Geoderma, 134, 200-206, 2006.

Tonitto, C., David, M. B., Li, C., and Drinkwater, L. E.: Application of the DNDC model to tile-drained Illinois agroecosystems: model comparison of conventional and diversified rotations, Nutr. Cycl. Agroecosyst., DOI 10.1007/s10705-006-9074$2,2007$.

Vleeshouwers, L. M. and Verhagen, A.: Carbon emission and sequestration by agricultural land use: a model study for Europe, Glob. Change Biol., 8, 519-530, 2002.

Vuichard, N., Ciais, P., Viovy, N., Calanca, P., and Soussana, J.-F.: Estimating the greenhouse gas fluxes of European Grasslands with a process-based model: Part 2. Simulations at the continental level, Global Biogeochem. Cy., 21, doi:10.1029/2005GB002612, 2007.

Wattenbach, M., Zebisch, M., Hattermann, F., Gottschalk, P., Goemann, H., Kreins, P., Badeck, F., Lasch, P., Suckow, F., and Wechsung, F.: Hydrological impact assessment of afforestation and change in tree-species composition - A regional case study for the Federal State of Brandenburg (Germany), J. Hydrol., doi.:10.1016/j.jhydrol.2007.08.005, 2007.

Weiske, A., Vabitsch, A., Olesen, J. E., Schelde, K., Michel, J., Friedrich, R., and Kaltschmitt, M.: Mitigation of greenhouse gas emissions in European conventional and organic dairy farming, Agriculture, Ecosystems \& Environment, 112, 221-232, 2006.

Xu-Ri, X. Wang, M., and Wang, Y.: Using a modified DNDC model to estimate $\mathrm{N}_{2} \mathrm{O}$ fluxes from semi-arid grassland in China, Soil Biol. Biochem., 35, 615-620, 2003. 